This item was submitted to Loughborough's Research Repository by the author.

Items in Figshare are protected by copyright, with all rights reserved, unless otherwise indicated.

\title{
Preparation of monodisperse multiple emulsions at high production rates by multi-stage premix membrane emulsification
}

\section{PLEASE CITE THE PUBLISHED VERSION}

http://dx.doi.org/10.1016/j.memsci.2004.07.008

PUBLISHER

(C) Elsevier

VERSION

AM (Accepted Manuscript)

\section{LICENCE}

CC BY-NC-ND 4.0

\section{REPOSITORY RECORD}

Vladisavljevic, Goran T., Masataka Shimizu, and Tadao Nakashima. 2012. "Preparation of Monodisperse Multiple Emulsions at High Production Rates by Multi-stage Premix Membrane Emulsification”. figshare. https://hdl.handle.net/2134/10554. 
This item was submitted to Loughborough's Institutional Repository (https://dspace.lboro.ac.uk/) by the author and is made available under the following Creative Commons Licence conditions.

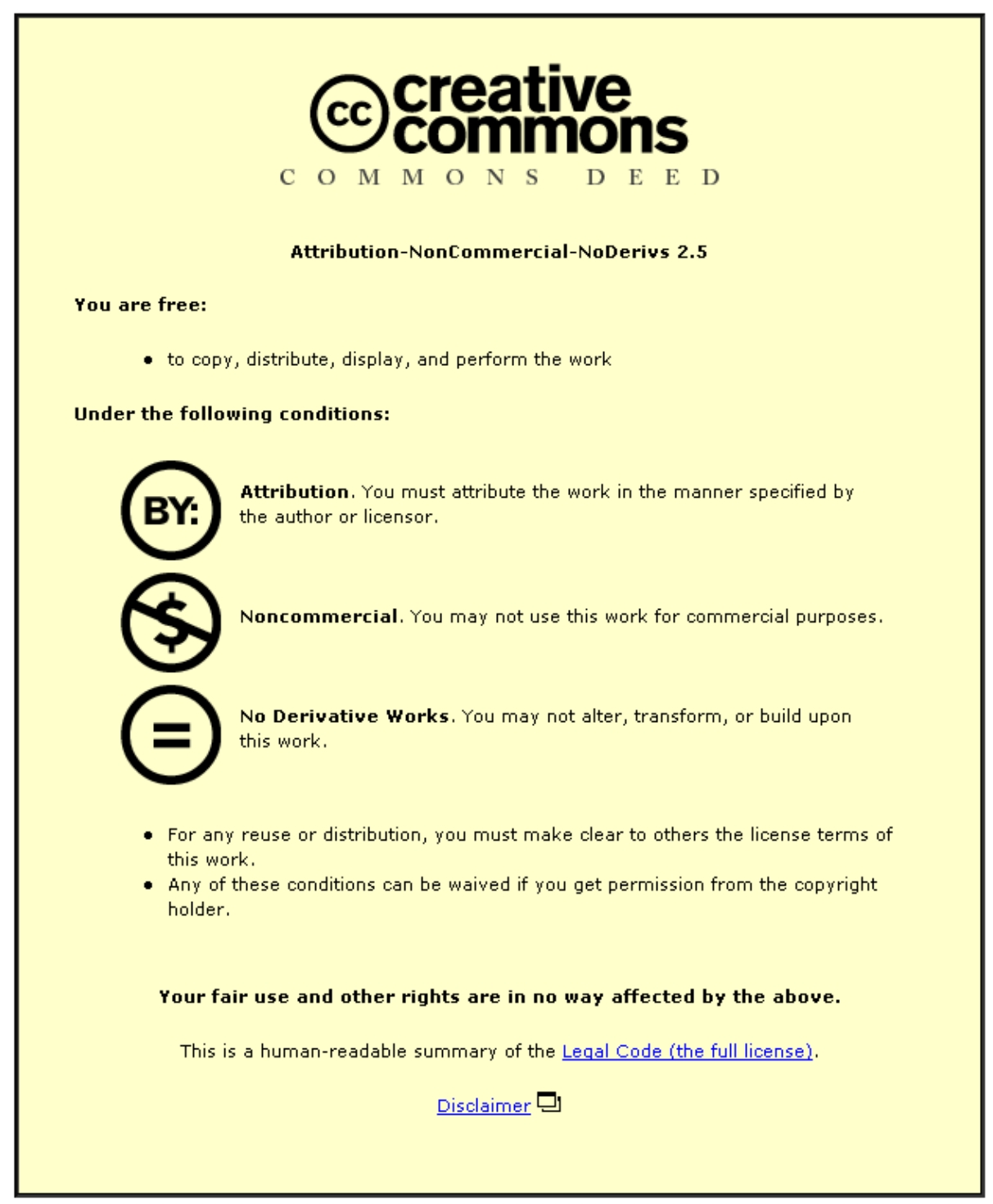

For the full text of this licence, please go to: http://creativecommons.org/licenses/by-nc-nd/2.5/ 


\section{Preparation of monodisperse multiple emulsions at high production rates by multi-stage premix membrane emulsification}

Goran T. Vladisavljević ${ }^{\mathrm{a}^{*}}$, Masataka Shimizu ${ }^{\mathrm{b}}$, Tadao Nakashima ${ }^{\mathrm{c}}$

${ }^{a}$ Institute of Food Technology and Biochemistry, Faculty of Agriculture, University of Belgrade, P.O. Box 127, YU-11081 Belgrade-Zemun, Serbia, Serbia and Montenegro.

${ }^{\mathrm{b}}$ Miyazaki Prefectural Industrial Technology Center, 16500-2 Higashi-Kaminaka, Sadowara, Miyazaki 880-0303, Japan.

cMiyazaki Prefectural Industrial Support Foundation, 16500-2 Higashi-Kaminaka, Sadowara, Miyazaki 880-0303, Japan.

\section{Abstract}

Multiple W/O/W emulsions have been prepared by multi-stage (repeated) premix membrane emulsification using Shirasu-porous-glass (SPG) membrane with a mean pore size of $10.7 \mu \mathrm{m}$. A coarse emulsion containing droplets with a mean particle size of about $100 \mu \mathrm{m}$ was homogenized 5-6 times through the same membrane at a constant pressure difference of 20-300 kPa to achieve additional droplet homogenization and size reduction. The optimum conditions with regard to particle size uniformity were 3 homogenization cycles at a pressure difference of $100 \mathrm{kPa}$, under which the mean size of outer $\mathrm{W} / \mathrm{O}$ particles was $9 \mu \mathrm{m}$ and the span of particle size distribution was as low as 0.28. The optimum pressure difference in a single-stage process was higher, but the 
particle size distribution of prepared emulsions was broader than in a multi-stage process at smaller pressures. The transmembrane flux was in the range of 1.8-37 $\mathrm{m}^{3} /\left(\mathrm{m}^{2} \mathrm{~h}\right)$ and increased with increasing pressure difference and decreasing the content of $\mathrm{W} / \mathrm{O}$ particles. The mean size of $\mathrm{W} / \mathrm{O}$ particles in each cycle was remarkably constant over a wide range of their concentration of 1-60 vol. \%.

Keywords: Membrane emulsification; Shirasu porous glass membrane; Multiple emulsion; Premix membrane emulsification; Monodisperse emulsion.

\section{Introduction}

Membrane emulsification (ME) involves the permeation of pure disperse phase through a microporous membrane into stirring or cross-flowing continuous phase (direct or conventional ME [1]) or the passage of coarse premix through the membrane (premix ME or membrane homogenization [2]). In direct ME, fine droplets are formed in situ at the membrane/continuous phase interface. The main disadvantage of direct ME is a small disperse phase flux through the membrane of $0.001-0.1 \mathrm{~m}^{3} /\left(\mathrm{m}^{2} \mathrm{~h}\right)$, that should be maintained to precisely control droplet size. In some direct ME investigations [3-4], the disperse phase flux was as high as $2.5 \mathrm{~m}^{3} /\left(\mathrm{m}^{2} \mathrm{~h}\right)$, but the droplet size was only roughly controlled. Due to low fluxes, direct ME is mainly used for the preparation of emulsions with relatively small disperse phase contents, up to 25 vol. \% [4-5]. However, direct ME using Shirasu-porous glass (SPG) membranes enables to obtain narrow droplet size distributions with the relative span factors of 0.26-0.45 $\left(\operatorname{span}=\left(\mathrm{d}_{90}-\mathrm{d}_{10}\right) / \mathrm{d}_{50}\right)[6-10]$.

In premix ME, large droplets of coarse premix are disrupted into fine droplets by utilizing a microporous membrane as a special kind of low-pressure homogenizing 
valve. Premix ME holds several advantages over direct ME: (1) The optimal fluxes with regard to droplet uniformity are typically above $1 \mathrm{~m}^{3} /\left(\mathrm{m}^{2} \mathrm{~h}\right)$, which is much higher than in direct ME; (2) The mean droplet sizes are smaller than in direct ME, which is often advantageous; (3) The experimental set-up is simpler than in direct ME, e.g. no moving parts such as cross-flow pump or stirrer are needed, except for the preparation of preemulsion; (4) Premix ME process is easier to control and operate than direct ME. One of the disadvantages of single premix $\mathrm{ME}$ is a higher emulsion polydispersity compared to direct ME [1]. In order to combine high transmembrane flux and narrow droplet size distribution, a multi-stage (repeated) premix ME can be applied [11-12].

In the first investigation on premix ME carried out by Suzuki et al. [2], premix was diluted by permeation into pure continuous phase/diluted emulsion recirculating at the low-pressure side of the membrane (Fig. 1a). Using SPG membranes with a mean pore size of 2.7 and $4.2 \mu \mathrm{m}$, Suzuki et al. [1] have prepared O/W emulsions with the relative span factors of $0.40-0.66$ at the fluxes of $0.029-3.55 \mathrm{~m}^{3} /\left(\mathrm{m}^{2} \mathrm{~h}\right)$. In the next studies [1314] a batch premix ME system was used, in which fine emulsion was withdrawn from the system after passing through the membrane, without any recirculation or dilution with the continuous phase (Fig. 1b). If the membrane wall is wetted with the disperse phase, the permeation is followed by phase inversion, i.e. a fine $\mathrm{W} / \mathrm{O}$ emulsion can be prepared from an $\mathrm{O} / \mathrm{W}$ premix (Fig. 1c) and vice versa. Using a batch cell equipped with PTFE membranes, Suzuki et al. [13-14] have prepared O/W and W/O emulsions with somewhat lower droplet size uniformity than O/W emulsions prepared using crossflow premix ME with SPG membranes, but at the fluxes as high as $13 \mathrm{~m}^{3} /\left(\mathrm{m}^{2} \mathrm{~h}\right)$. The cross-flow premix ME exhibits several disadvantages over batch premix ME: (a) fine emulsion is diluted by mixing with pure continuous phase, which makes difficult or 
impossible to reach high disperse phase contents in fine emulsion; (b) the cross-flow system is complicated by the presence of pump and additional pipelines and fittings; (c) there is a risk of droplet break-up by a cross-flow pump. On the other hand, cross-flow premix ME can be operated as a semi-continuous or continuous process, while oncethrough premix ME is inevitably a batch process.

Shima et al. [15] have prepared fine W/O/W emulsions by passing a coarse W/O/W emulsion through a disposable membrane cartridge or a membrane holder equipped with cellulose acetate membranes. The mean pore size in their investigation was in the range of $0.2-3 \mu \mathrm{m}$, and the mean droplet size in fine emulsions was 1.0-3.5 times greater than the mean pore size.

The extent of droplet disruption in premix ME is closely related to the wall shear stress inside the membrane pores, given by:

$\sigma_{\mathrm{w}, \mathrm{p}}=8 \eta_{\mathrm{e}} \mathrm{J} \xi /\left(\varepsilon \mathrm{d}_{\mathrm{m}}\right)$

where $\eta_{\mathrm{e}}$ is the mean viscosity of emulsion inside the pores, $\xi$ is the mean tortuosity factor of the pores, $\varepsilon$ is the mean membrane porosity, $d_{m}$ is the mean pore size, and $J$ is the transmembrane flux.

At the transmembrane pressures smaller than a critical pressure $\mathrm{p}_{c}$, the droplets larger than the pore size are completely retained by the membrane, i.e. under these conditions membrane emulsification is not possible (Fig. 2a). At the transmembrane pressures above this critical pressure, all droplets pass through the membrane, irrespective of their size. However, at smaller shear stresses inside the pores, the final droplet size, $d_{2}$, is larger than the pore size, $d_{m}$. In that case the large droplets of the initial diameter $d_{1}$ are deformed at the pore inlets to enter the pores, followed by disruption due to friction between the droplets and the pore walls. The fine droplets are deformed again at the 
pore outlets to regain a spherical shape (Fig. 2b). At higher shear stresses, the droplets are more intensively disrupted inside the pores due to collisions between the droplets and collisions with the pore walls, so that the final droplet size can be smaller than the pore size (Fig. 2c). In that case, the deformation of droplets at the pore outlets does not occur, since the final droplet size is smaller than the pore size.

If the initial droplet size $d_{1}$ is not much larger than the pore size $d_{m}$, i.e. for $d_{1} / d_{m}$ ratio close to unity, the critical pressure is given by [16]:

$$
\mathrm{p}_{\mathrm{c}}=\frac{\gamma_{\mathrm{O} / \mathrm{w}}\left[2+2 \mathrm{a}^{6} / \sqrt{2 \mathrm{a}^{6}-1} \times \arccos \left(1 / \mathrm{a}^{3}\right)-4 \mathrm{a}^{2}\right]}{\mathrm{a}+\sqrt{\mathrm{a}^{2}-1}}
$$

where $\mathrm{a}=\mathrm{d}_{1} / \mathrm{d}_{\mathrm{m}}$ and $\gamma_{\mathrm{O} / \mathrm{w}}$ is the interfacial tension at oil/water interface. If the initial droplet size is much larger than the pore size $\left(\mathrm{d}_{1} / \mathrm{d}_{\mathrm{m}}\right.$ » 1$)$, the critical pressure is equal to the capillary pressure commonly used in direct ME:

$\mathrm{p}_{\mathrm{c}}=\frac{4 \gamma_{\mathrm{O} / \mathrm{w}} \cos \theta}{\mathrm{d}_{\mathrm{m}}}$

where $\theta$ is the contact angle between disperse phase droplets and membrane surface in continuous phase.

In this investigation, a novel method of multi-stage batch premix ME was used to produce multiple $\mathrm{W} / \mathrm{O} / \mathrm{W}$ emulsions suitable for use in drug delivery systems. The fine emulsion was repeatedly passed through the same SPG membrane to achieve additional droplet homogenization and size reduction. The span of particle size distribution as low as 0.28 was obtained at the transmembrane fluxes exceeding $20 \mathrm{~m}^{3} /\left(\mathrm{m}^{2} \mathrm{~h}\right)$ in some experiments. The final mean droplet size was either smaller or larger than the mean pore size, depending on the operating conditions. The effect of driving pressure, content of apparent oil drops, and number of homogenization cycles on transmembrane flux, mean droplet size, and the span of particle size distribution was investigated. 


\section{Experimental}

\subsection{Materials}

The oil phase in $\mathrm{W}_{1} / \mathrm{O} / \mathrm{W}_{2}$ emulsion was 5 wt. \% polyglycerol polyricinoleate (PGPR) dissolved in soybean oil. PGPR was obtained from Sakamoto Yakuhin Kogyo Co. (Japan) and the soybean oil with a saponification value of 188-197, an iodine value of $123-142$ and a density at $298 \mathrm{~K}$ of $920 \mathrm{~kg} / \mathrm{m}^{3}$ was purchased from Wako Pure Chemical Industries, Ltd. (Japan). The inner aqueous phase $\mathrm{W}_{1}$ contained 5 wt. \% D(+)glucose as the osmotic additive. The outer aqueous phase $\mathrm{W}_{2}$ contained 0.5 wt. \% Tween 80 (polyoxyethylene (20) sorbitan monooleate) as emulsifier, 5 wt. \% D(+)glucose as the osmotic additive, and 1 wt. \% sodium alginate. The role of sodium alginate was to increase the viscosity of outer aqueous phase $W_{2}$, thus reducing the creaming tendency of large $\mathrm{W}_{1} / \mathrm{O}$ drops prior to membrane homogenization. The role of glucose was to increase the osmotic pressure in both aqueous phases to approximately 0.78 MPa, which is the osmotic pressure of blood and other body liquids and thus, to ensure the stability of prepared multiple emulsions in drug delivery systems. The emulsion formulation is given in Tab. 1. Everywhere in this paper, the term oil drops will be referred to the drops of oil containing fine $\mathrm{W}_{1}$ droplets.

The viscosity of continuous phase measured by a Tokimec model DVL-B digital rotational viscometer under the conditions of a No. 5 rotor was 126 and $146 \mathrm{mPa} \cdot \mathrm{s}$ at 303 and $297 \mathrm{~K}$, respectively.

\subsection{Membranes}


The experiments have been carried out using SPG membrane tubes (8.5 mm inner diameter $\times 0.8 \mathrm{~mm}$ wall thickness) supplied from SPG Technology Co., Ltd (Sadowara, Japan). The mean pore size of the membrane was $10.7 \mu \mathrm{m}$, the mean porosity was 55.2 $\%$, and the mean tortuosity factor of the pores 1.3 . The membrane was cleaned after use by dipping in ethanol and toluene (2 days in ethanol plus 2 days in toluene), followed by heating at $500{ }^{\circ} \mathrm{C}$ for $30 \mathrm{~min}$ in an Advantec model KM-420 electric muffle furnace. The inherent properties of the SPG membranes used were completely restored by this treatment.

\subsection{Experimental set-up and procedure}

$\mathrm{W}_{1} / \mathrm{O} / \mathrm{W}_{2}$ emulsions were prepared by a two-step emulsification procedure. The $\mathrm{W}_{1} / \mathrm{O}$ emulsion was prepared by means of a homomixer (Ultra Turrax ${ }^{\circledR}$, model T25, IKA Works, USA) at 24,000 rpm for $5 \mathrm{~min}$. The primary $\mathrm{W}_{1} / \mathrm{O}$ emulsion was then mixed with the outer aqueous phase $\mathrm{W}_{2}$ by means of a stirring bar to prepare a $\mathrm{W}_{1} / \mathrm{O} / \mathrm{W}_{2}$ premix. The premix was then homogenized by permeation through the SPG membrane using a membrane emulsification apparatus manufactured by Kiyomoto Iron Works Ltd. (Fig. 3). The advantage of using membrane emulsification at the second step of the emulsification procedure is to get high entrapment efficiency of active substance(s) in the inner droplets, owing to a small and controlable shear stress inside the pores.

The effective membrane length in the module was $12 \mathrm{~mm}$ and the effective crosssectional membrane area was $3.75 \mathrm{~cm}^{2}$. The pressure vessel was filled with $100 \mathrm{ml}$ of the premix and the required transmembrane pressure was built-up with compressed nitrogen. The fine emulsion which has passed through the membrane was collected into a beaker placed on a Mettler Toledo model PR 5002 precision balance. The balance was 
interfaced to a PC computer to collect time and mass data every $1 \mathrm{~s}$ using a WIN for METTLER software. The premixes were emulsified 5-6 times through the same membrane without cleaning the membrane between the cycles and the emulsion samples obtained after each cycle were collected and analyzed. The experiments have been carried out at $297 \mathrm{~K}$.

Droplet size distribution was determined using a Shimadzu model SALD-2000 laser diffraction particle size analyzer, which allows the detection of droplets in the range of 0.03-280 $\mu \mathrm{m}$ with the resolution of 50 channels. The mean droplet size was expressed as the $d_{50}$ diameter. The photographs of obtained droplets were taken using an Olympus PM-CP-3 Polaroid camera attached to an Olympus BH-2 microscope.

\section{Results and discussion}

\subsection{Effect of transmembrane pressure on emulsification result}

The influence of transmembrane pressure on the transmembrane flux and the mean size of oil drops at the content of $\mathrm{W}_{1}$ droplets of $\varphi_{\mathrm{i}}=0.1$ and the content of oil drops in the outer aqueous phase of $\varphi_{\mathrm{o}}=0.1$ is shown in Figs. 4 and 5. It is clear that $\mathrm{J}$ increased with increasing $\Delta \mathrm{p}_{\mathrm{tm}}$, which led to a more intensive droplet break-up and smaller mean particle size at the higher pressures. The same behavior was observed earlier by Suzuki et al. [2, 13] in premix ME with SPG and PTFE membranes. It is in contrast to the experimental results in direct ME [10,17], in which mean droplet size at small driving pressures (in the so-called size-stable zone) is independent on driving pressure and then increases with the further pressure increase (in the size-expanding zone).

The smaller mean particle sizes at the larger pressures are a consequence of the higher shear stresses inside the pores. For an example, substituting $\eta_{\mathrm{e}}=0.19 \mathrm{~Pa} \mathrm{~s}$ into 
Eq. (1), one obtains the wall shear stress of 80 and $1740 \mathrm{~Pa}$ in a single-stage process $(\mathrm{n}=1)$ at the pressure of 20 and $150 \mathrm{kPa}$, respectively. As shown in Fig. 4, the transmembrane flux increased linearly with the driving pressure, indicating that the fouling resistance was constant for the given operating conditions. It must be noted here that the slope of the J vs. $\Delta \mathrm{p}_{\mathrm{tm}}$ line strongly depended on the content of inner droplets in oil drops and oil drops in W/O/W emulsion. It is in agreement with the results reported by Altenbach-Rehm et al. [12], who found that in premix ME with PTFE membranes the permeating flux increased almost linearly with the pressure difference at disperse phase (oil) concentrations of 10-30 vol. \%.

The transmembrane flux in Fig. 4 was $0.85-22.7 \mathrm{~m}^{3} /\left(\mathrm{m}^{2} \mathrm{~h}\right)$, which was at least 3 orders of magnitude higher than in direct ME with the same membrane. On the other hand, the mean size of homogenized droplets was smaller than the mean pore size for all operating conditions, except after first pass through the membrane at 20 and $40 \mathrm{kPa}$ (Fig. 5). In direct ME with SPG membranes, the mean droplet size is typically 3-4 times higher than the mean pore size $[15,10]$. The ratio of mean droplet to mean pore size of 0.73-1.2 observed here after first pass is much smaller than 2-3.7, found by Suzuki et al. [13] in premix ME with PTFE membranes, which can be attributed to significantly higher mean pore size in this work.

Transmembrane pressure is used here to overcome flow resistances in the pores and interfacial tension forces, i.e. to deform and disrupt large oil drops into smaller droplets:

$\Delta \mathrm{p}_{\mathrm{tm}}=\Delta \mathrm{p}_{\text {flow }}+\Delta \mathrm{p}_{\text {disr }}$

According to the Darcy's law, the pressure loss for overcoming flow resistances in the pores, $\Delta \mathrm{p}_{\text {flow }}$, should be proportional to the transmembrane flux, while the expenditure 
of pressure for droplet disruption, $\Delta \mathrm{p}_{\text {disr }}$, is proportional to the increase in the interfacial area. If transmembrane pressure is kept constant $\left(\Delta \mathrm{p}_{\mathrm{tm}}=\right.$ const $)$, it can be written:

$$
\Delta \mathrm{p}_{\mathrm{tm}}=\eta_{\mathrm{e}}\left(\mathrm{R}_{\mathrm{m}}+\mathrm{R}_{\mathrm{fi}}\right) J_{\mathrm{i}}+\mathrm{C} \varphi_{\mathrm{o}} \gamma_{\mathrm{o} / \mathrm{w}}\left(1 / \mathrm{d}_{\mathrm{i}}-1 / \mathrm{d}_{\mathrm{i}-1}\right)=\text { const }
$$

The first and the second term in the right-hand side of Eq. (5) express $\Delta \mathrm{p}_{\text {flow }}$ and $\Delta \mathrm{p}_{\text {disr }}$, respectively. Here, $C$ is a parameter independent on the number of cycles, $\mathrm{J}_{\mathrm{i}}$ and $\mathrm{d}_{\mathrm{i}}$ are the transmembrane flux and the resulting mean particle size corresponding to the ith cycle, $\mathrm{R}_{\mathrm{m}}$ is the hydraulic resistance of clean membrane, and $\mathrm{R}_{\mathrm{fi}}$ is the overall fouling resistance in the ith cycle. The fouling resistance is a consequence of the accumulation of oil drops on the membrane surface (external fouling) and inside the pores (internal fouling).

\subsection{Effect of number of passes and dispersed phase content on emulsification result}

As shown in Fig. 6, the flux increases with increasing the number of passes, because the second term in the right-hand side of Eq. (5) diminishes until it becomes negligible for $\mathrm{d}_{\mathrm{i}-1} \approx \mathrm{d}_{\mathrm{i}} \approx$ const. Figs. 9 and 10 indicate that at constant experimental conditions the mean particle size tends to a limiting constant value, as the number of cycles increases. The largest flux increase was observed in the second pass, as the largest particle size reduction occurred in the first pass.

The variation of $\Delta \mathrm{p}_{\text {flow }}$ and $\Delta \mathrm{p}_{\text {disr }}$ with the number of emulsification cycles at $\Delta \mathrm{p}_{\mathrm{tm}}=$ 20 and $150 \mathrm{kPa}$ is shown in Fig. 7. The values of $\Delta \mathrm{p}_{\text {flow }}$ and $\Delta \mathrm{p}_{\text {disr }}$ were calculated from Eqs. (4) and (5) by adopting the fluxes $\mathrm{J}_{\mathrm{i}}$ from Fig. 6 and assuming that the limiting flux was established after 5 passes through the membrane. For the operating conditions as in Fig. 7, in the first pass about $25 \%$ of the overall pressure drop was used for droplet disruption, the remaining being used for overcoming flow resistances in the pores. 
Because the content of oil drops in Fig. 7 was only 10 vol. \%, it should be expected that at sufficiantly high dispersed phase contents, the majority of driving pressure in the first pass through the membrane is used for overcoming interfacial tension forces. Due to a substantial energy dissipation for droplet disruption, the mean droplet size in the first pass was reduced 4-9 times. In the subsequent cycles, the mean droplet size continued to decrease but at a decreasing rate. Therefore, the pressure drop due to droplet disruption progressively decreased, until it became negligible after 5 passes. On the other hand, $\Delta \mathrm{p}_{\text {flow }}$ increased with increasing the number of cycles and reached the overall pressure drop $\Delta \mathrm{p}_{\mathrm{tm}}$ after 5 cycles.

Fig. 8 shows that the transmembrane flux significantly decreases with increasing the content of oil drops, $\varphi_{0}$, which is a consequence of the fact that the disruption term in Eq. (5) is directly proportional to the disperse phase content. For dilute emulsions $\left(\varphi_{0}=\right.$ 1 vol. \%), the disruption term can be ignored and the flux is given only by the flowresistances term. Under these conditions the maximum flux was observed in the first cycle corresponding to a minimum fouling resistance and emulsion viscosity. Over the $\varphi_{o}$ range of 5-10 vol. \%, the maximum flux was observed in the third pass. Presumably, for $\mathrm{n}<3$ the flux was more affected by a decrease in $\Delta \mathrm{p}_{\text {disr }}$ then by an increase in the fouling resistance and consequently, $\mathrm{J}$ increased with $\mathrm{n}$. For $\mathrm{n}>3$, a decrease in the disruption term became less significant then an increase in the fouling resistance and $\mathrm{J}$ decreased with further increase in n. For concentrated emulsions, the maximum flux was observed in the final stage $(n=5)$, which is the same type of behavior as in Fig. 6 .

Fig. 9 demonstrates that at the given operating conditions, the mean droplet size was independent on the content of oil drops over a wide range of 1-60 vol. \%, in spite of the fact that the flux was significantly smaller at the higher contents of oil drops (Fig. 8 and 
11). It differs from behavior in high-pressure homogenizers, in which the mean droplet size at a constant operating pressure may be significantly dependent on the disperse phase content, even in the range of 0.05-0.2 vol. \% [18]. The behavior shown in Fig. 9 can be explained by the fact that in the absence of coalescence the mean size of homogenized oil droplets is primarily dictated by the mean pore size and the applied shear stress inside the pores. Eq. (1) implies that the shear stress inside the pores is proportional to the product $\mathrm{J} \eta_{\mathrm{e}}$. At higher disperse phase content, the flux $\mathrm{J}$ is smaller, but the emulsion viscosity $\eta_{\mathrm{e}}$ is higher, so that under certain experimental conditions the shear stress inside the pores may become independent on the disperse phase content. In premix ME with PTFE membranes, an increase in disperse phase content resulted in an increase of mean droplet size [12]. The higher the transmembrane pressure was, the less the changes of disperse phase concentration effected the mean droplet size [12].

Except at the content of oil drops of 60 vol. \%, the optimum number of cycles with regard to monodispersity was 3-4 (Fig. 9). Altenbach-Rehm et al. [12] found that multistage premix ME with polymeric PTFE membranes also resulted in a smaller mean droplet size and narrower droplet size distribution than a single-stage process. The optimum number of cycles in their investigation was 2-3, but the minimum relative span factor was 0.55-0.7, which is substantially higher than in our study.

Fig. 10 illustrates the influence of operating pressure on the flux vs. disperse phase content curves for $n=1$. It can be seen that the effect of operating pressure on the flux is more marked at the smaller disperse phase contents. At a content of oil drops of 60 vol. \%, the transmembrane flux was not influenced by the pressure in the investigated range of $100-150 \mathrm{kPa}$. However, at $\varphi_{\mathrm{o}}=1 \mathrm{vol} . \%$, the flux increased by a factor of 2 , as the pressure increased from 100 to $150 \mathrm{kPa}$. It can be explained by the fact that in the 
region of small oil drops contents, the pressure difference is predominantly used for overcoming flow resistance forces, while at high disperse phase contents, the pressure drop is mainly used for overcoming interfacial tension forces, that are independent on the transmembrane flux.

Fig. 11 shows that the optimum number of cycles with regard to droplet uniformity strongly depends on the transmembrane pressure. At the pressure of 100 and $150 \mathrm{kPa}$, the minimum span of particle size distribution of 0.28 and 0.35 , respectively was reached after three passes. At the same pressures, a single stage process $(n=1)$ resulted in the relative span factors of 0.55 and 0.42 , respectively (Figs. 12a and 12b). The smallest pressure of $100 \mathrm{kPa}$ was the optimum pressure with regard to droplet size uniformity when three emulsification cycles were performed, but the least favorable pressure in a single-stage process. It shows that in a single-pass process, the optimum pressure is considerably higher than in a multi-pass process. It is also worth of mentioning here that at the highest pressure of $300 \mathrm{kPa}$, the most uniform particles were prepared after first pass, but the least uniform after three passes through the membrane (Fig. 12c).

The micrographs of emulsion particles before and after homogenization taken by optical microscope under the same magnification are shown in Figs. 13a-13c. As shown in Fig. 13a, the particles of coarse emulsion (premix) were relatively large and highly polydisperse (some portion of the particles was larger than $300 \mu \mathrm{m}$, but 0.7 vol. \% were smaller than $15 \mu \mathrm{m}$ ). The minimum particle size in the premix was $12 \mu \mathrm{m}$, which was above the mean pore size. After first pass through the membrane, 96 vol. \% of the particles were smaller than $15 \mu \mathrm{m}$, but the remaining 4 vol. \% were still in the range of 15-37 $\mu \mathrm{m}$ (Fig. 13b). Obviously, the driving pressure of $100 \mathrm{kPa}$ was not large enough 
to finely break up all particles of coarse emulsion in a single pass. However, when homogenization was repeated 6 times, all particles were smaller than $10.4 \mu \mathrm{m}$ and highly uniform, as shown in Fig. 13c.

\section{Conclusions}

The experiments reported here have demonstrated that the multi-stage (repeated) premix ME using SPG membranes enables to obtain multiple W/O/W emulsions with very narrow particle size distribution $(\operatorname{span}=0.28)$ at high production rates. The higher the transmembrane pressure, the smaller number of cycles was necessary to reach a narrow particle size distribution. However, much better results with regard to particle size uniformity were obtained using several passes (usually 2-4) at smaller pressures, than a single pass at higher pressures. At the contents of oil drops of $20 \mathrm{vol}$. \% or above, the transmembrane flux in the subsequent cycles was progressively higher approaching to a maximum limiting value, as the number of passes increased. It was explained by a decreasing proportion of the total pressure difference used for droplet deformation and disruption. The mean droplet size in the subsequent passes was smaller and smaller tending to a limiting value determined by the magnitude of the shear stress inside the membrane pores. The permeation rate through the membrane considerably decreased with increasing the content of oil drops, but the mean size of oil drops was unaffected.

Our further study of multi-stage premix membrane emulsification will be focused on the effects of interfacial tension, mean pore size, and the viscosity of continuous phase on the emulsification results.

\section{List of Symbols}


a ratio of initial particle size to pore size $\left(\mathrm{d}_{1} / \mathrm{d}_{\mathrm{m}}\right)$, -

C constant in Eq. (5), -

$\mathrm{d}_{1} \quad$ initial particle size, $\mathrm{m}$

$\mathrm{d}_{\mathrm{m}} \quad$ mean pore size of membrane, $\mathrm{m}$

$d_{50} \quad$ mean particle size of emulsion, $m$

$\mathrm{J} \quad$ transmembrane flux, $\mathrm{m} \mathrm{s}^{-1}$

n number of homogenization cycles, -

$\mathrm{p}_{\mathrm{c}} \quad$ critical pressure, $\mathrm{Pa}$

$\Delta \mathrm{p}_{\mathrm{tm}} \quad$ transmembrane pressure, $\mathrm{Pa}$

$\Delta \mathrm{p}_{\text {flow }}$ pressure loss for overcoming flow resistances in the pores, $\mathrm{Pa}$

$\mathrm{q}_{3} \quad$ volume frequency of particles, $\mathrm{m}^{-1}$

$\mathrm{R}_{\mathrm{m}} \quad$ hydrodynamic resistance of clean membrane, $\mathrm{m}^{-1}$

$\mathrm{R}_{\mathrm{f}} \quad$ fouling resistance, $\mathrm{m}^{-1}$

span relative span factor of particle size distribution, -

$\varepsilon \quad$ porosity of membrane wall, -

$\eta_{\mathrm{e}} \quad$ mean viscosity of emulsion inside pores, Pa s

$\varphi_{\mathrm{i}} \quad$ concentration of inner droplets of $\mathrm{W}_{1}$ phase in oil drops, vol. $\%$

$\varphi_{\mathrm{o}} \quad$ concentration of oil drops in outer aqueous phase, vol. \%

$\gamma_{\mathrm{O} / \mathrm{w}}$ interfacial tension at oil/water interface, $\mathrm{N} \mathrm{m}^{-1}$

$\theta \quad$ contact angle between oil and membrane surface in continuous phase, rad

$\sigma_{\mathrm{w}, \mathrm{p}} \quad$ wall shear stress inside pores, $\mathrm{Pa}$

$\xi \quad$ mean tortuosity factor of pores, - 
i refers to ith stage of membrane homogenization

w refers to water

\section{Acknowledgement.}

The authors wish to thank the Japan Society for the Promotion of Science (JSPS), Tokyo, Japan for the financial support of this work.

\section{References}

[1] S.M. Joscelyne and G. Trägårdh, Membrane emulsification - a literature review, J. Membr. Sci., 169 (2000) 107.

[2] K. Suzuki, I. Shuto and Y. Hagura, Characteristics of the membrane emulsification method combined with preliminary emulsification for preparing corn oil-in-water emulsions, Food Sci. Technol. Int. Tokyo, 2 (1996) 43.

[3] A.J. Abrahamse, R. van Lierop, R.G.M. van der Sman, A. van der Padt and R.M. Boom, Analysis of droplet formation and interactions during cross-flow membrane emulsification, J. Membr. Sci., 204 (2002) 125.

[4] R. Katoh, Y. Asano, A. Furuya, K. Sotoyama and M. Tomita, Preparation of food emulsions using a membrane emulsification system, J. Membr. Sci., 113 (1996) 131.

[5] R.A. Williams, S.J. Peng, D.A. Wheeler, N.C. Morley, D. Taylor, M. Whalley and D.W. Houldsworth, Controlled production of emulsions using a crossflow membrane, Chem. Eng. Res. Des., 76A (1998) 902. 
[6] T. Nakashima, M. Shimizu and M. Kukizaki, Effect of surfactant on production of monodispersed O/W emulsion in membrane emulsification, Kagaku Kogaku Ronbunshu, 19 (1993) 991.

[7] M. Shimizu, T. Nakashima and M. Kukizaki, Preparation of W/O emulsion by membrane emulsification and optimum conditions for its monodispersion, Kagaku Kogaku Ronbunshu, 28 (2002) 310.

[8] M. Shimizu, T. Nakashima and M. Kukizaki, Particle size control of W/O emulsion by means of osmotic pressure as driving force, Kagaku Kogaku Ronbunshu, 28 (2002) 304.

[9] G.T. Vladisavljević, U. Lambrich, M. Nakajima and H. Schubert, Production of $\mathrm{O} / \mathrm{W}$ emulsions using SPG membranes, ceramic $\alpha-\mathrm{Al}_{2} \mathrm{O}_{3}$ membranes, microfluidizer and a microchannel plate - a comparative study, Colloid. Surface. A, 232 (2004) 199.

[10] G.T. Vladisavljević and H. Schubert, Influence of process parameters on droplet size distribution in SPG membrane emulsification and stability of prepared emulsion droplets, J. Membr. Sci., 225 (2003) 15.

[11] J. Altenbach-Rehm, H. Schubert and K. Suzuki, Premix-Membranemulgieren mittels hydrophiler und hydrophober PTFE-Membranen zur Herstellung von O/W-Emulsionen mit enger Tropfengrößenverteilung, Chemie Ingenieur Technik, 74 (2002) 587.

[12] J. Altenbach-Rehm, K. Suzuki and H. Schubert, Production of O/W-emulsions with narrow droplet size distribution by repeated premix membrane emulsification, in: Proceedings of the $3^{\text {rd }}$ World Congress on Emulsions, Lyon, France, 2002, 2-B-051. 
[13] K. Suzuki, I. Fujiki and Y. Hagura, Preparation of corn oil/water and water/corn oil emulsions using PTFE membranes, Food Sci. Technol. Int. Tokyo, 4 (1998) 164.

[14] K. Suzuki, I. Fujiki and Y. Hagura, Preparation of high concentration of O/W and W/O emulsions by the membrane phase inversion emulsification using PTFE membranes, Food Sci. Technol. Int. Tokyo, 5 (1999) 234.

[15] M. Shima, Y. Kobayashi, T. Fujii, M. Tanaka, Y. Kimura, S. Adachi and R. Matsuno, Preparation of fine W/O/W emulsion through membrane filtration of coarse $\mathrm{W} / \mathrm{O} / \mathrm{W}$ emulsion and disappearence of the inclusion of outer phase solution, Food Hydrocolloids, 18 (2004) 61.

[16] S.H. Park, T. Yamaguchi and S. Nakao, Transport mechanism of deformable droplets in microfiltration of emulsions, Chem. Eng. Sci., 56 (2001) 3539.

[17] V. Schröder, O. Behrend and H. Schubert, Effect of dynamic interfacial tension on the emulsification process using microporous, ceramic membranes, J. Colloid Interface Sci., 202 (1998) 334.

[18] S. Brösel and H. Schubert, Investigations on the role of surfactants in mechanical emulsification using a high-pressure homogenizer with an orifice valve, Chem. Eng. Process., 38 (1999) 533. 


\section{TABLES}

Table 1. The formulation of $\mathrm{W}_{1} / \mathrm{O} / \mathrm{W}_{2}$ emulsions prepared in this work.

Inner aqueous phase, $\mathrm{W}_{1}$

5 wt. \% glucose dissolved in distilled water

Oil phase

5 wt. \% PGPR dissolved in soybean oil

Outer aqueous phase, $\mathrm{W}_{2}$

0.5 wt. \% Tween 80, 1 wt. \% sodium alginate, and 5 wt. \% glucose dissolved in distilled water

Volume percent of inner aqueous

phase in $\mathrm{W}_{1} / \mathrm{O}$ emulsion

$\varphi_{\mathrm{i}}=10-30$ vol. $\%$

Volume percent of $\mathrm{W}_{1} / \mathrm{O}$ emulsion

drops in $\mathrm{W}_{1} / \mathrm{O} / \mathrm{W}_{2}$ emulsion

$\varphi_{\mathrm{o}}=1-60$ vol. $\%$

Mean size of inner aqueous phase

$0.37-0.54 \mu \mathrm{m}$

Mean size of homogenized oil droplets

$4.4-13.2 \mu \mathrm{m}$ 


\section{FIGURE CAPTIONS}

Fig. 1. Premix membrane emulsification (ME) systems.

Fig. 2. Droplet break-up in premix ME: (a) droplet retention below a critical pressure; (b) moderate break up at moderate shear stresses $\left(\mathrm{d}_{\mathrm{m}}<\mathrm{d}_{2}<\mathrm{d}_{1}\right)$;

(c) intensive break up at high shear stresses $\left(\mathrm{d}_{2}<\mathrm{d}_{\mathrm{m}}<\mathrm{d}_{1}\right)$.

Fig. 3. Experimental set-up for premix ME used in this study.

Fig. 4. Effect of transmembrane pressure on transmembrane flux.

Fig. 5. Effect of transmembrane pressure on the mean size of oil drops.

Fig. 6. Transmembrane flux as a function of number of emulsification cycles at different transmembrane pressures.

Fig. 7. Variation of the pressure drop terms given in Eq. (4) with number of emulsification cycles.

Fig. 8. Transmembrane flux as a function of number of emulsification cycles at different contents of oil drops. 
Fig. 9. Variation of mean particle size and the span of particle size distribution with number of cycles at different contents of oil drops.

Fig. 10. Effect of the content of oil drops on transmembrane flux at two different transmembrane pressures (single pass through the membrane).

Fig. 11. Variation of mean particle size and the span of particle size distribution as a function of number of cycles at different transmembrane pressures.

Fig. 12a. Effect of number of cycles on particle size distribution at $\Delta \mathrm{p}_{\mathrm{tm}}=100 \mathrm{kPa}$. The dashed line represents the mean pore size.

Fig. 12b. Effect of number of cycles on particle size distribution at $\Delta \mathrm{p}_{\mathrm{tm}}=150 \mathrm{kPa}$. The dashed line represents the mean pore size.

Fig. 12c. Effect of number of cycles on particle size distribution at $\Delta \mathrm{p}_{\mathrm{tm}}=300 \mathrm{kPa}$. The dashed line represents the mean pore size.

Fig. 13a. Photograph of large premix particles before membrane homogenization $\left(\mathrm{d}_{50} \approx 100 \mu \mathrm{m}\right)$.

Fig. 13b. Photograph of fine particles obtained after first pass through the membrane $\left(d_{50}=10.8 \mu \mathrm{m}\right.$, span $=0.53$, experimental conditions as in Fig. 12a $)$. 
Fig. 13c. Photograph of fine particles obtained after six passes $\left(d_{50}=8.8 \mu \mathrm{m}\right.$, span $=$ 0.30, experimental conditions as in Fig. 12a). 


\section{FIGURES}

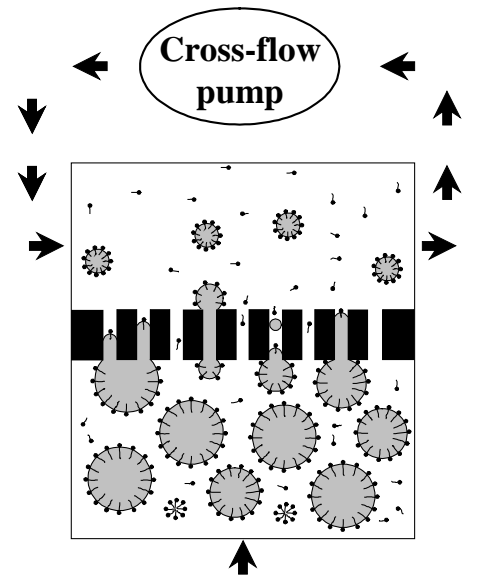

a. Cross-flow premix ME

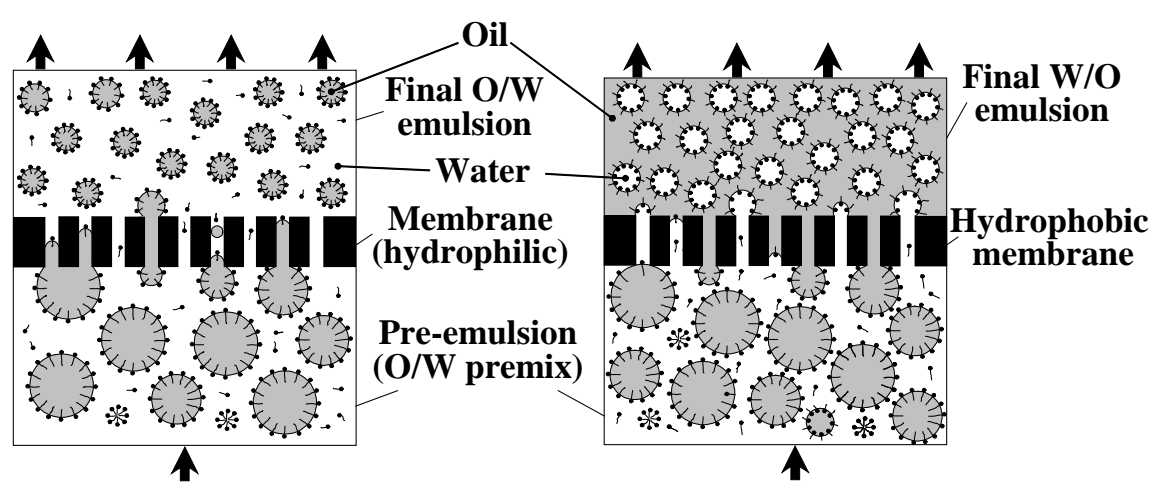

b. Batch premix ME without phase inversion c. Batch premix ME with phase inversion

Fig. 1, Vladisavljević et al. 


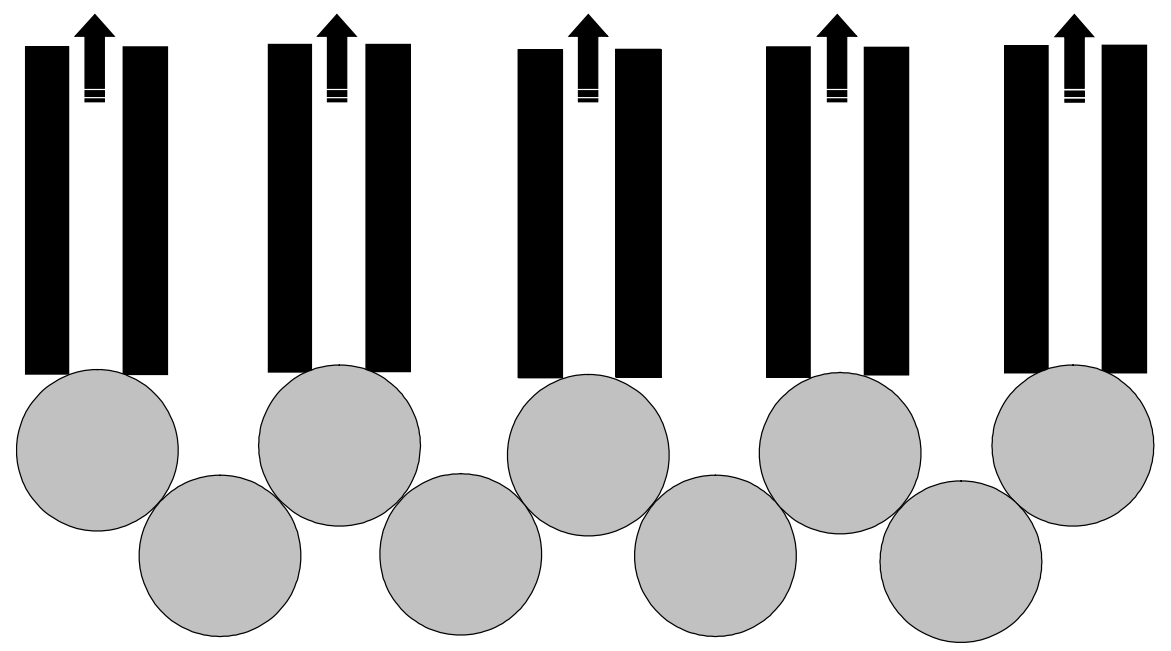

(a)
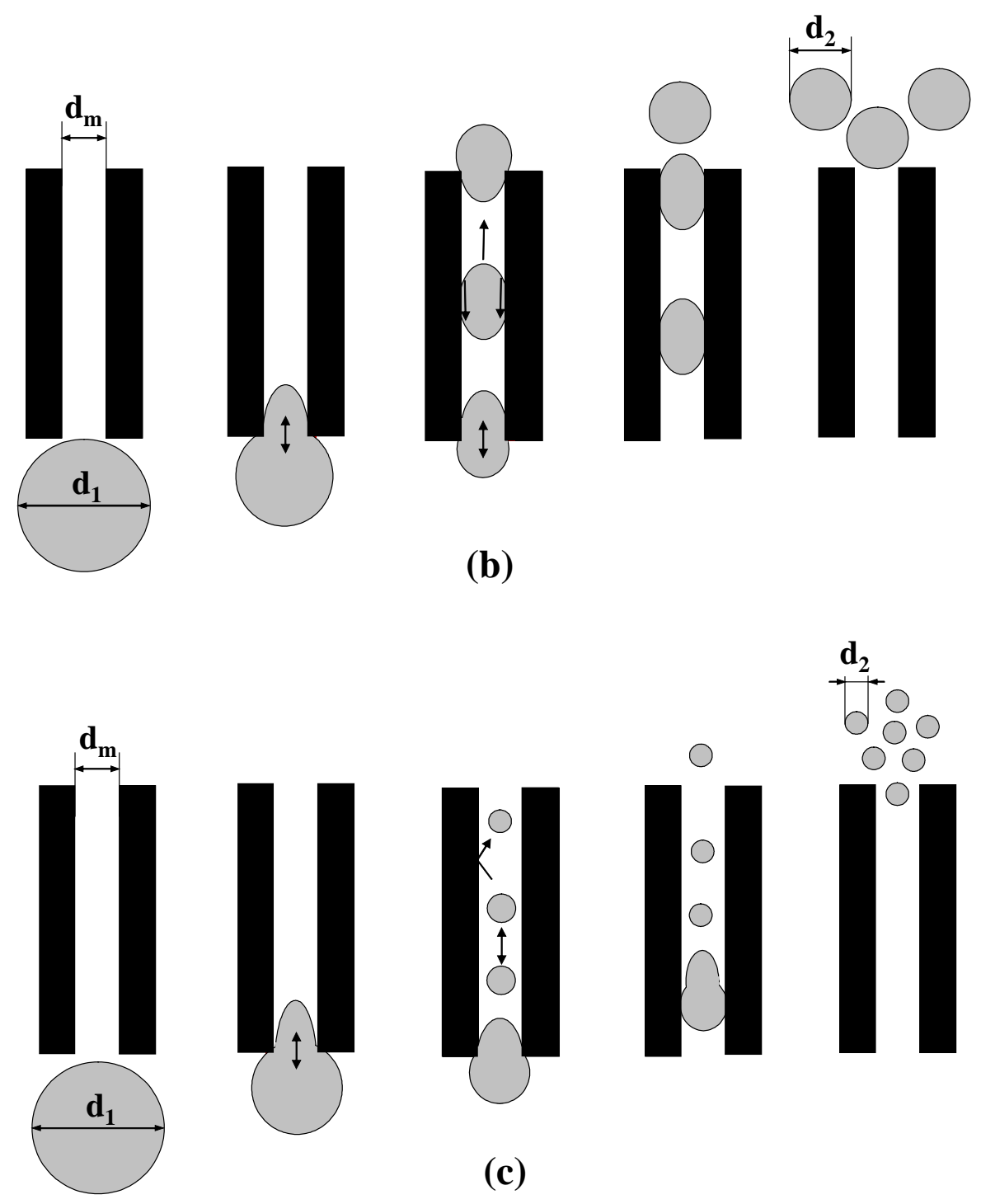

(b)

Fig. 2, Vladisavljević et al. 


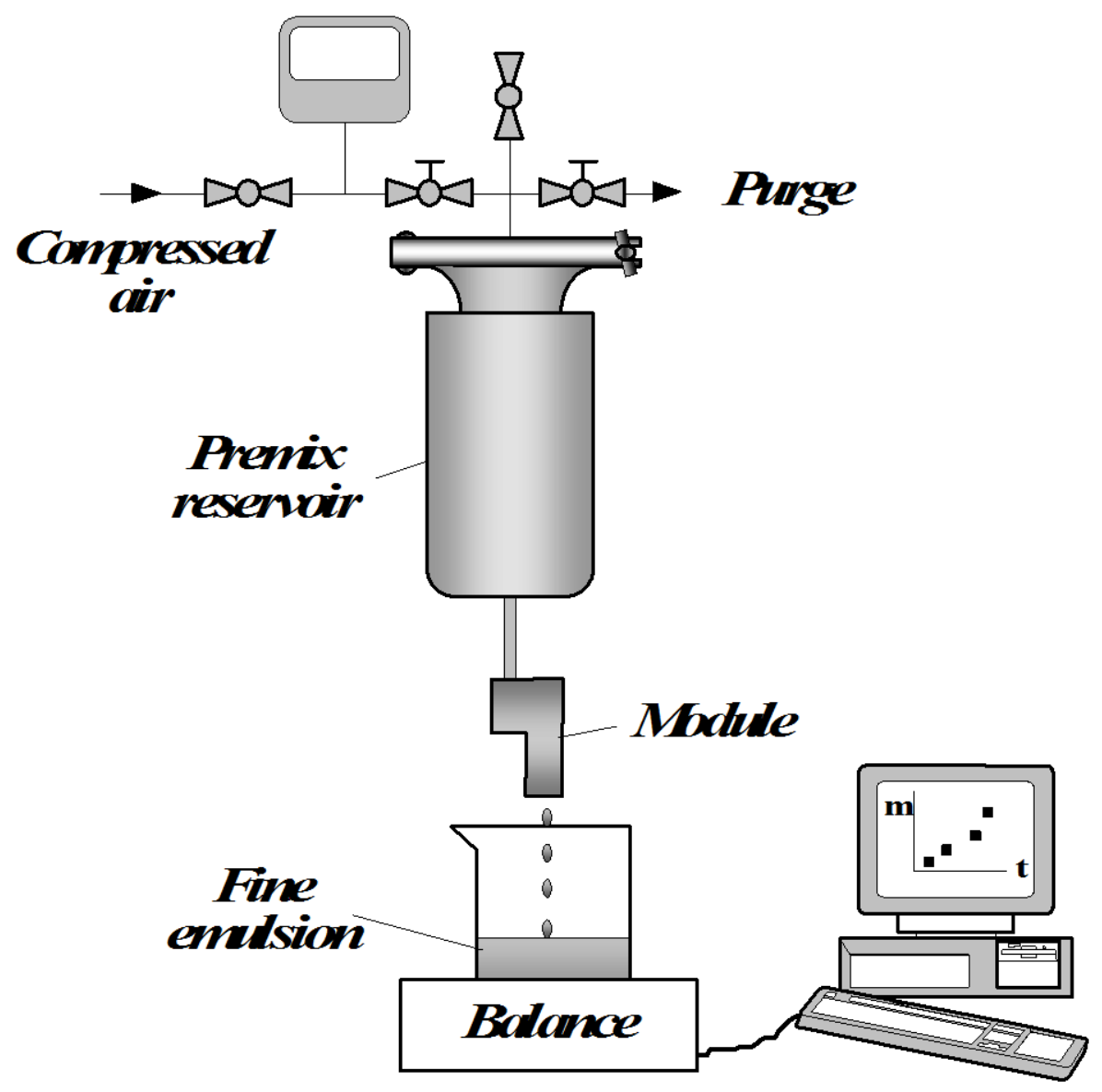

Fig. 3, Vladisavljević et al. 


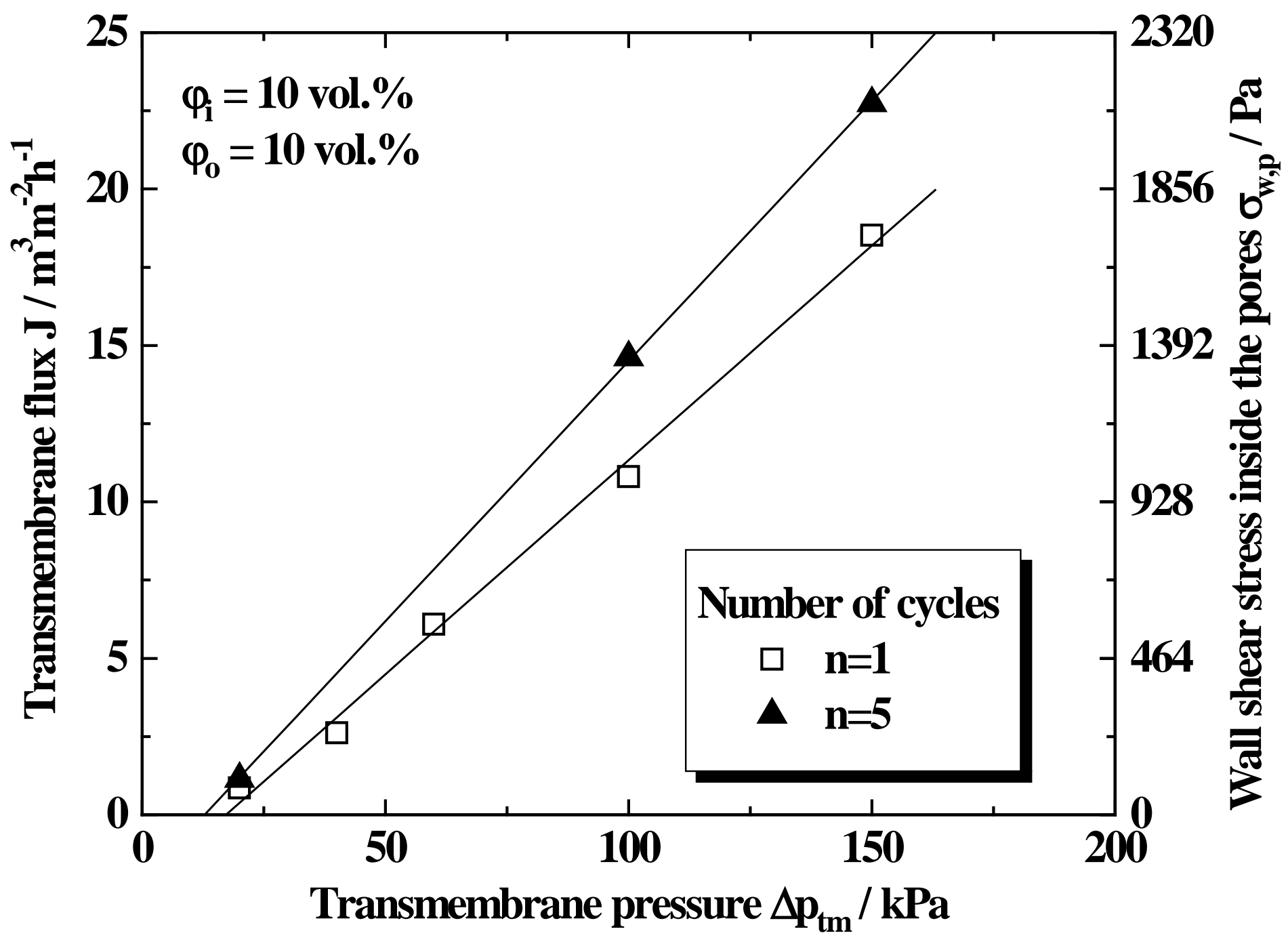

Fig. 4, Vladisavljević et al. 


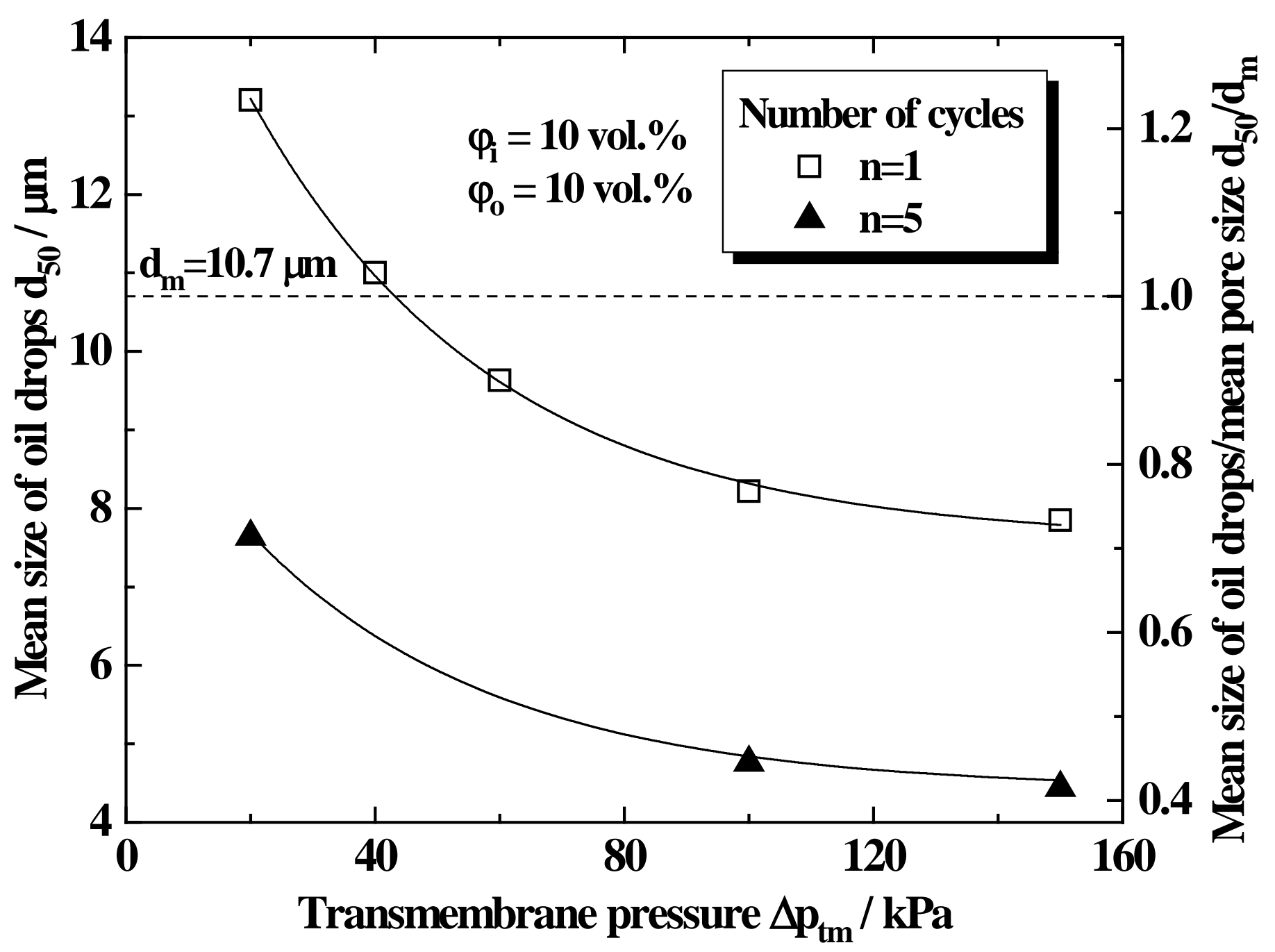

Fig. 5, Vladisavljević et al. 


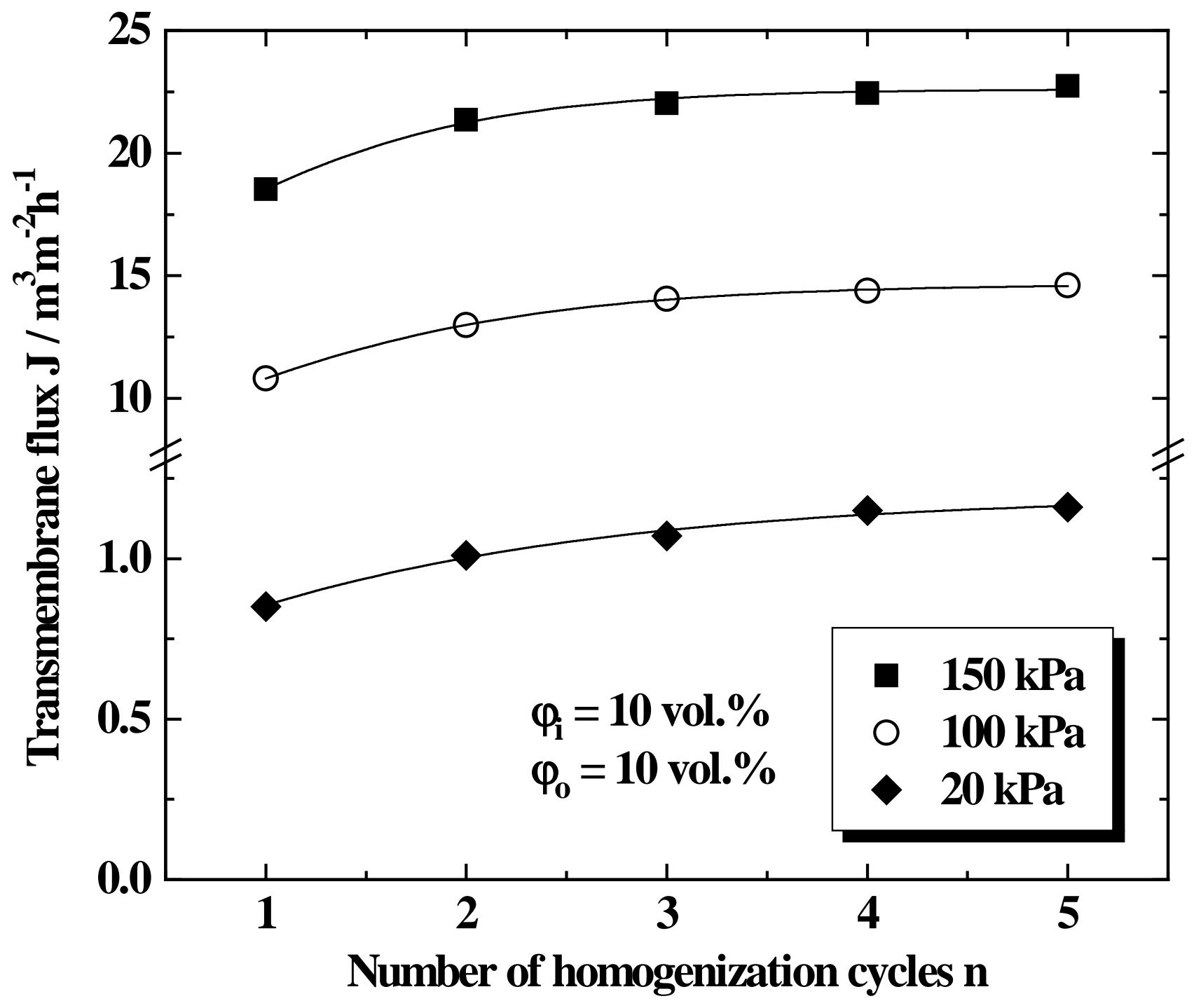

Fig. 6, Vladisavljević et al. 


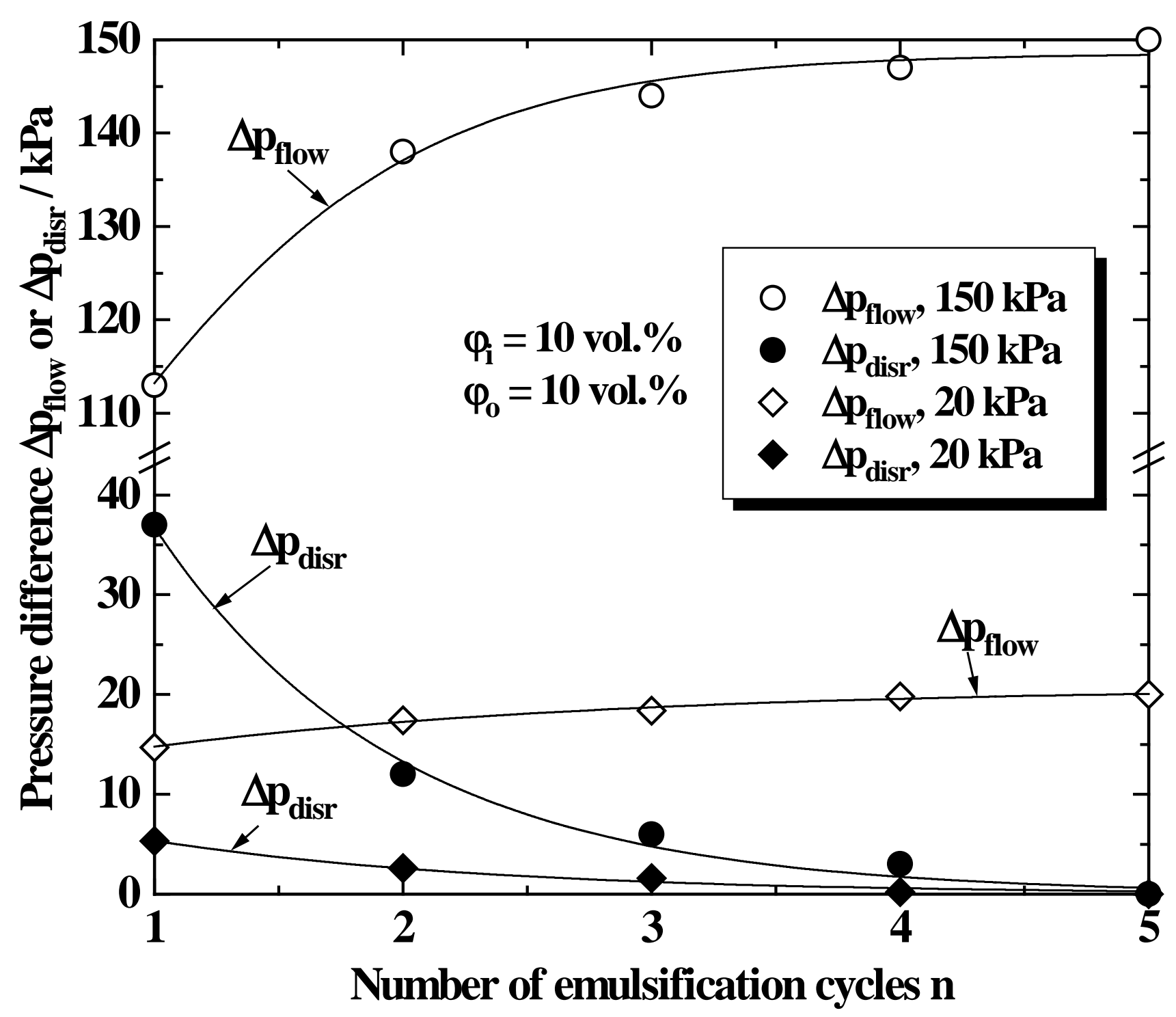

Fig. 7, Vladisavljević et al. 


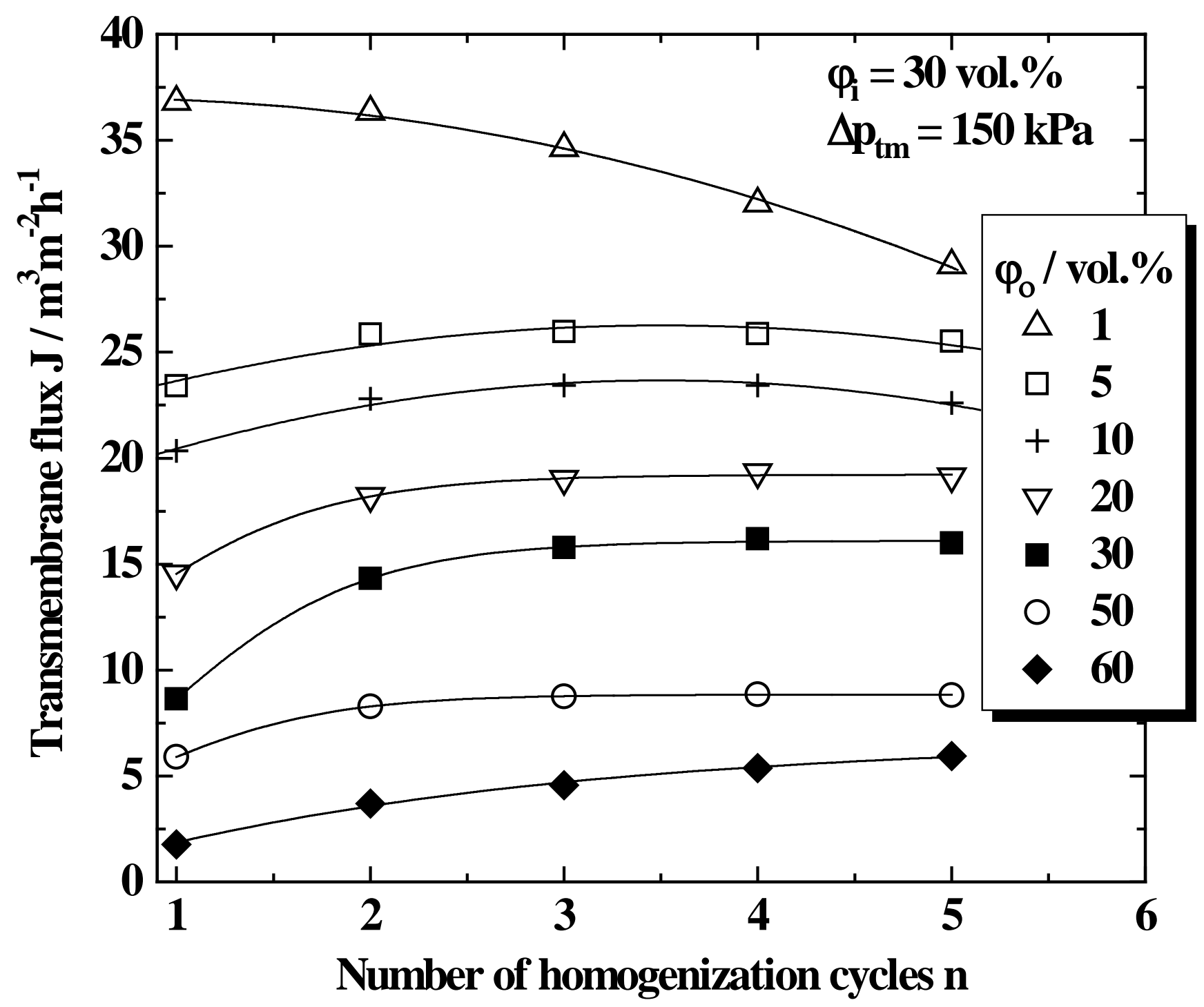

Fig. 8, Vladisavljević et al. 


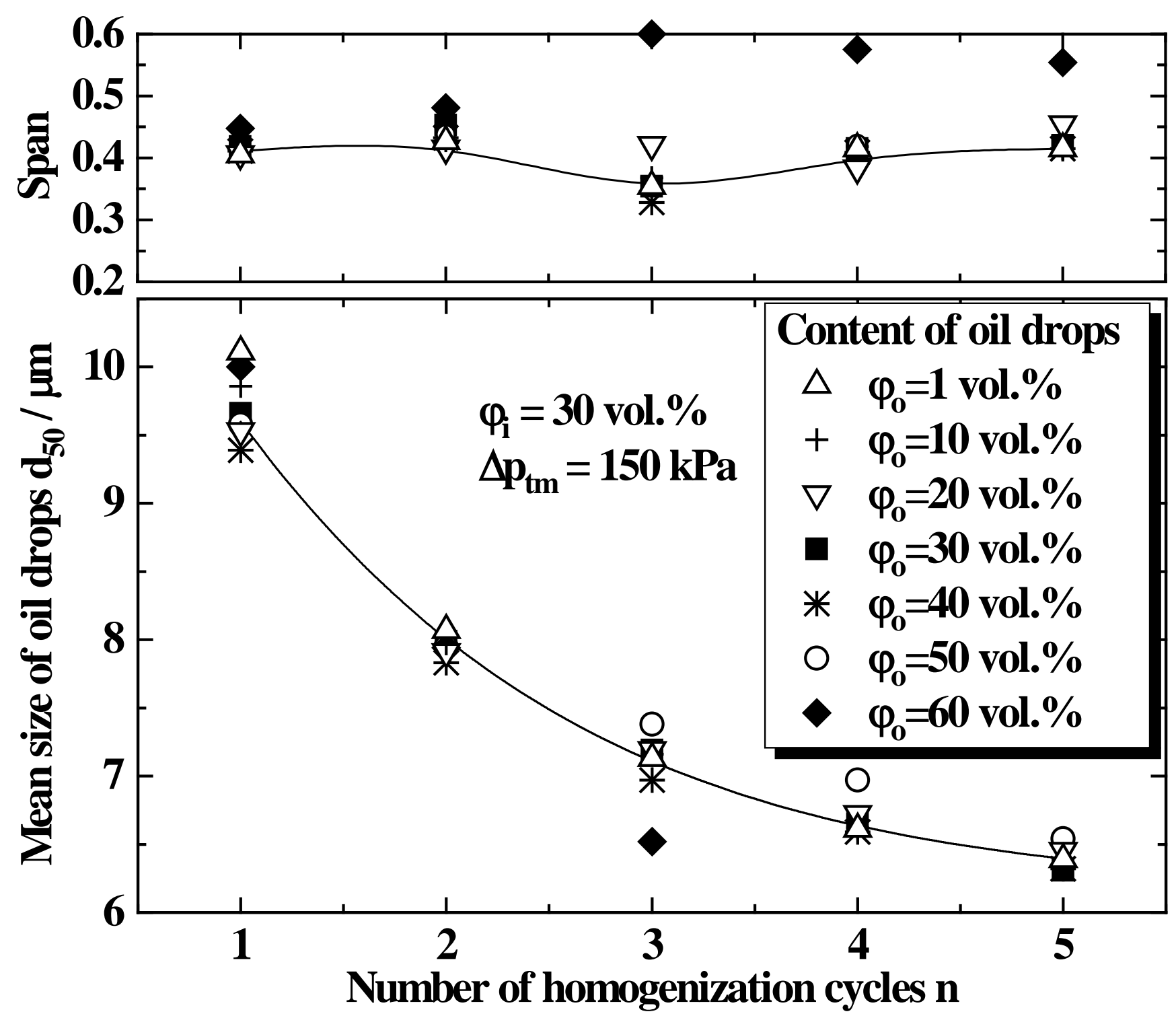

Fig. 9, Vladisavljević et al. 


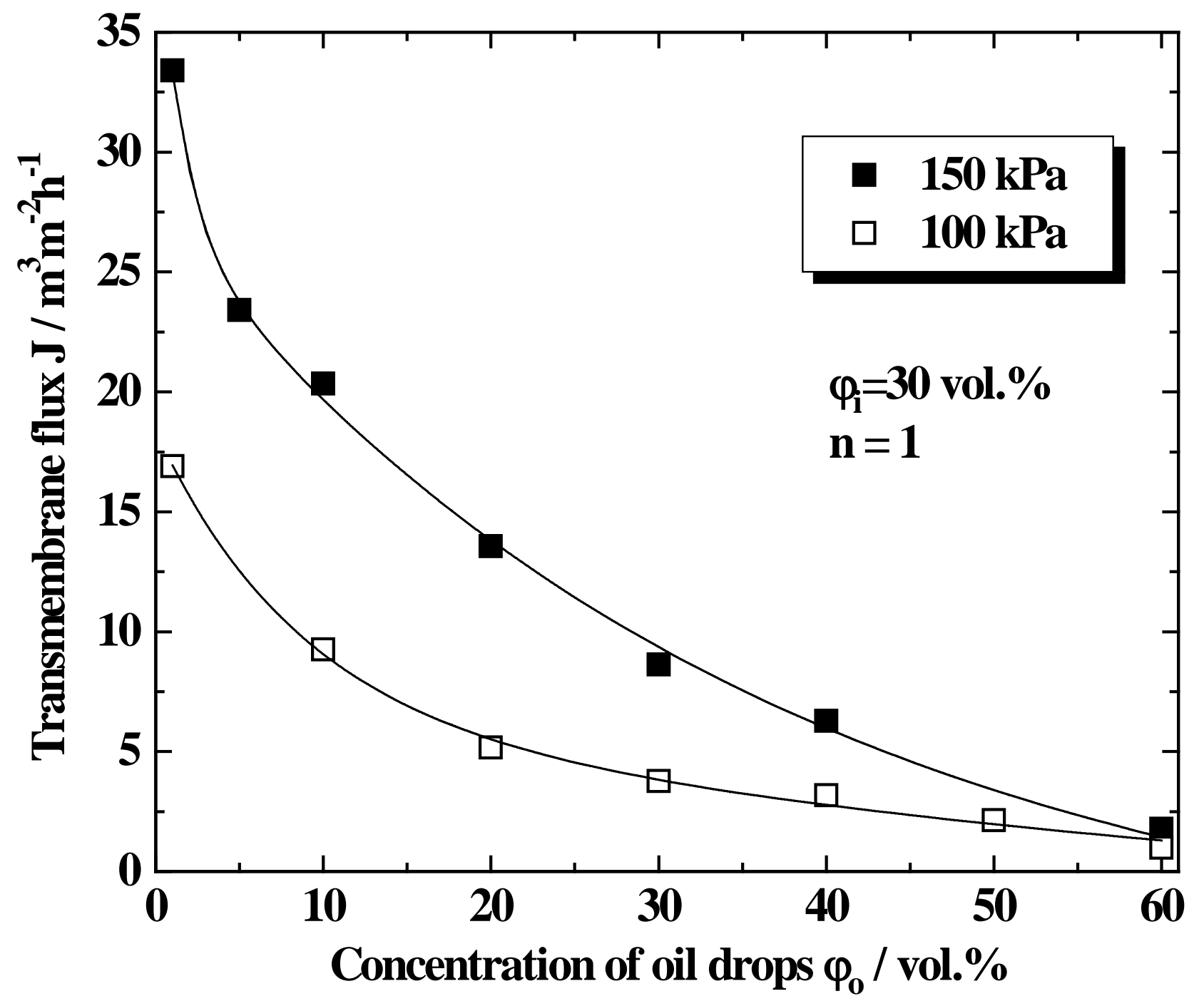

Fig. 10, Vladisavljević et al. 


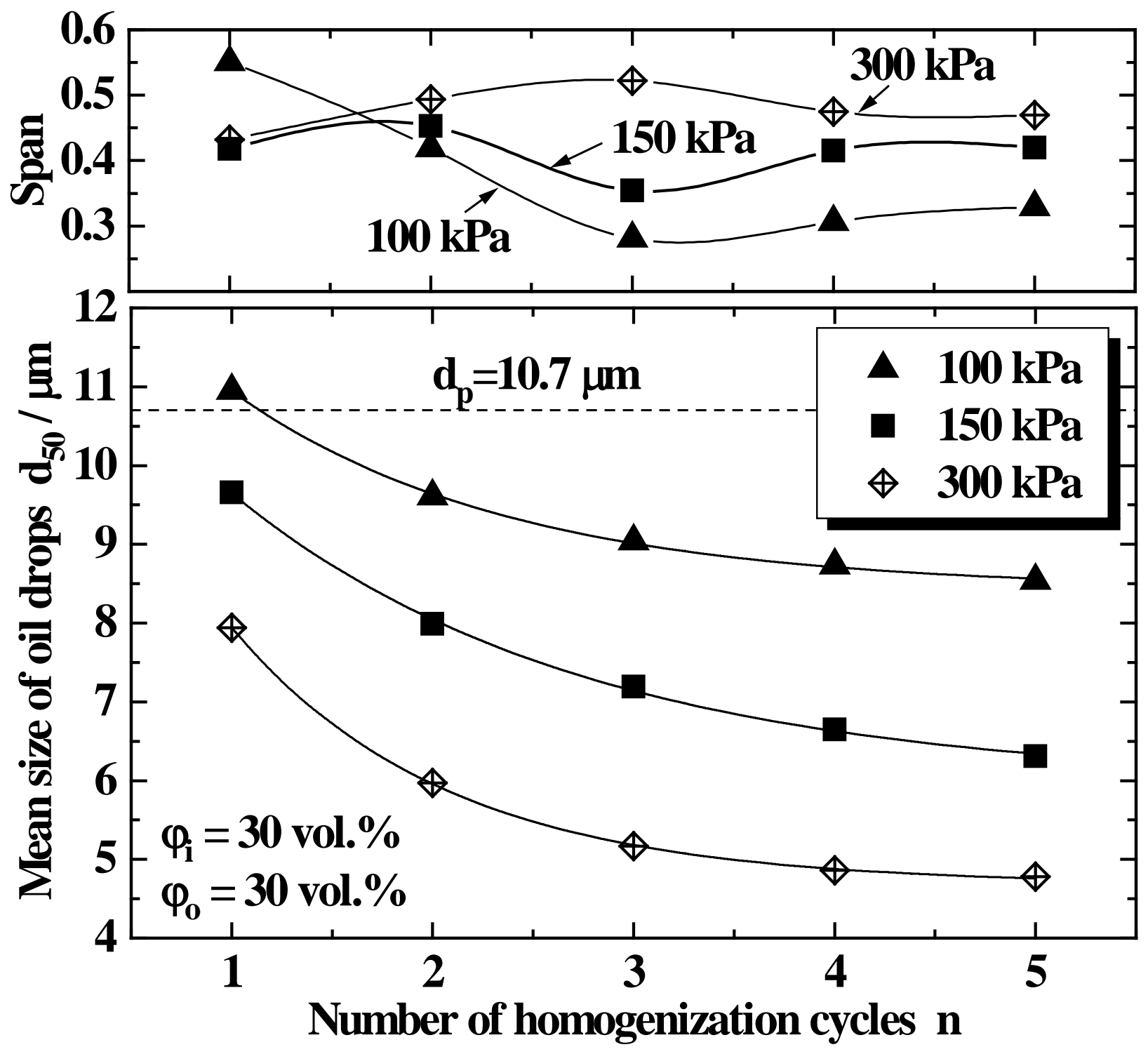

Fig. 11, Vladisavljević et al. 


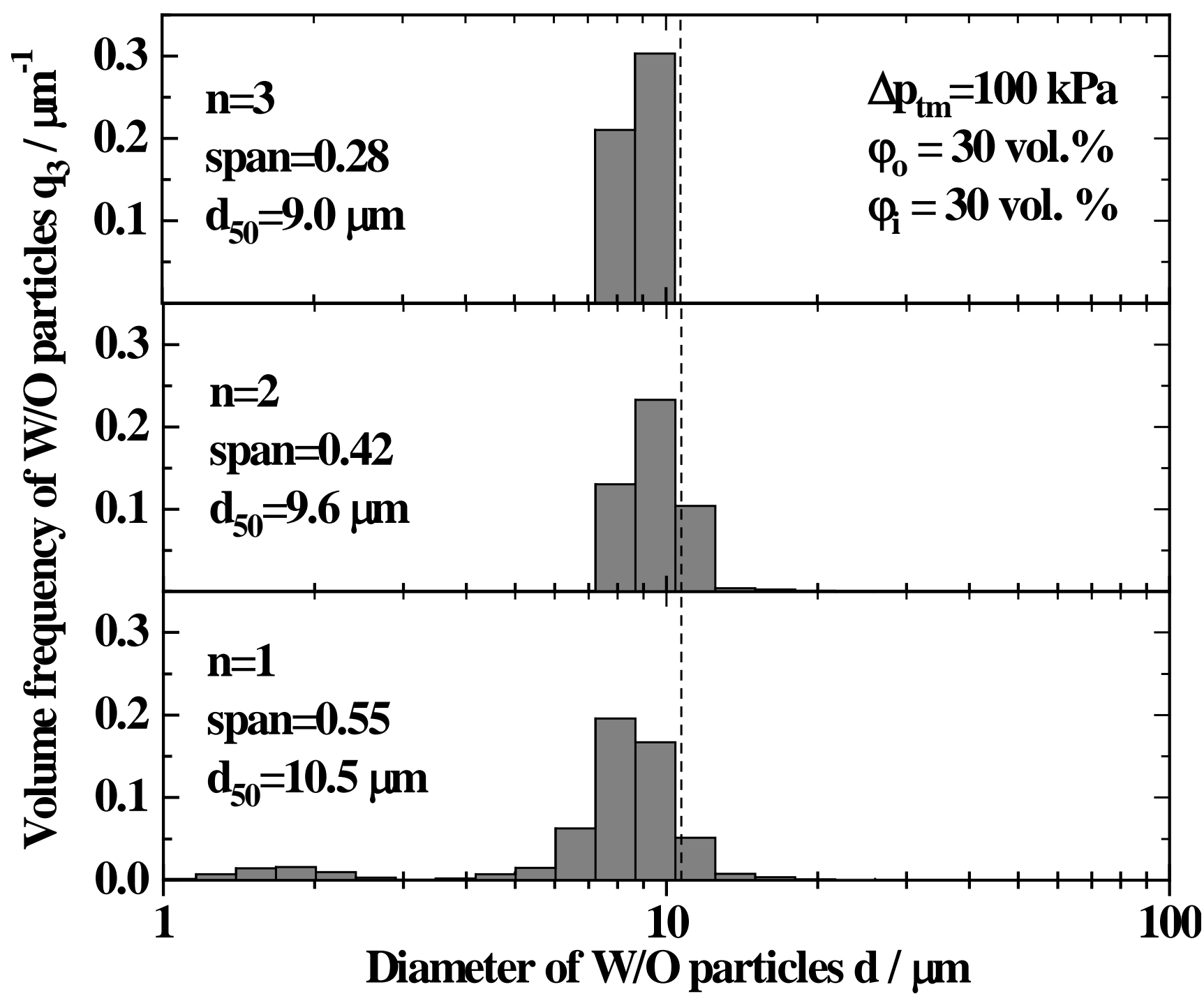

Fig. 12a, Vladisavljević et al. 


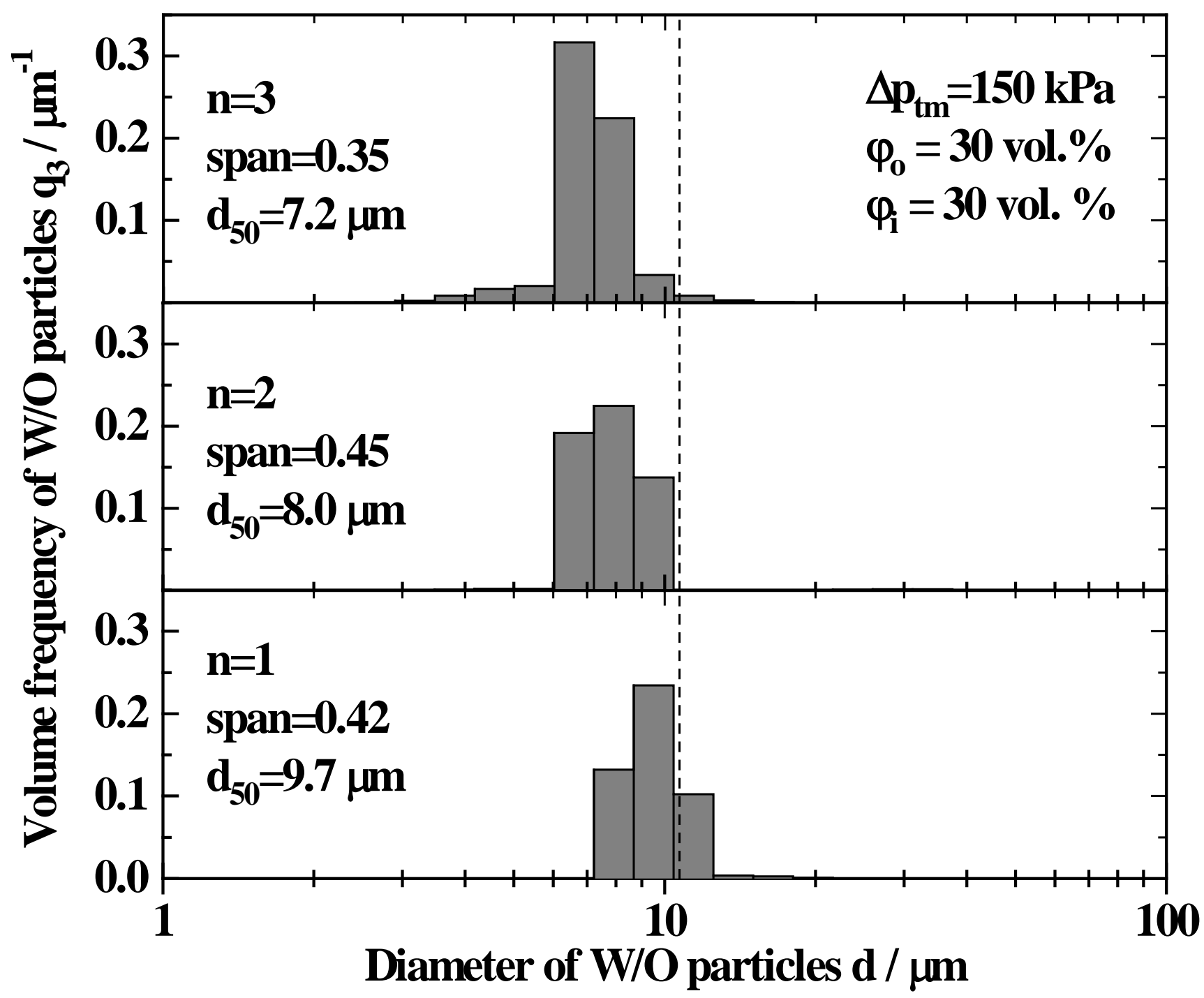

Fig. 12b, Vladisavljević et al. 


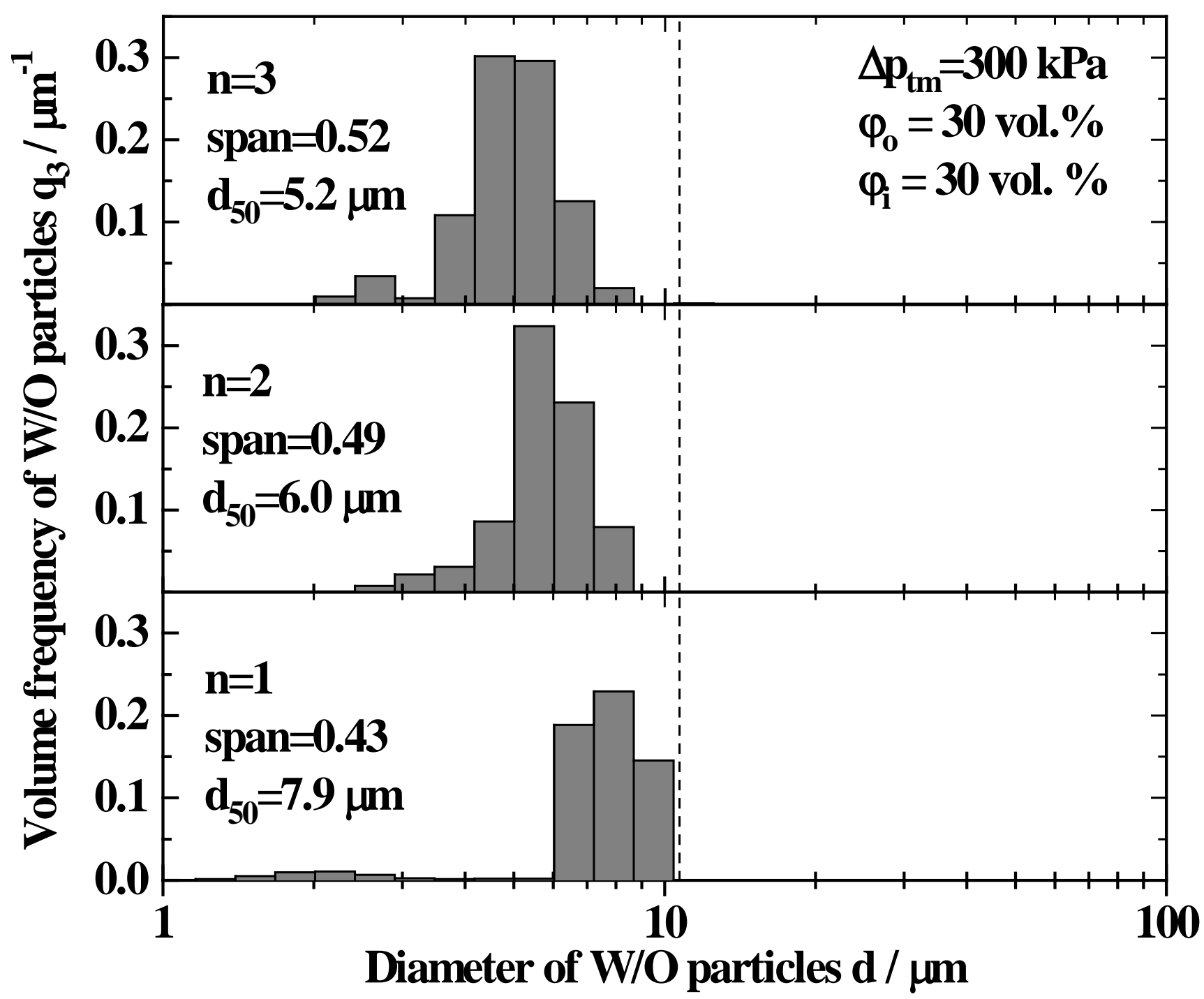

Fig. 12c, Vladisavljević et al. 


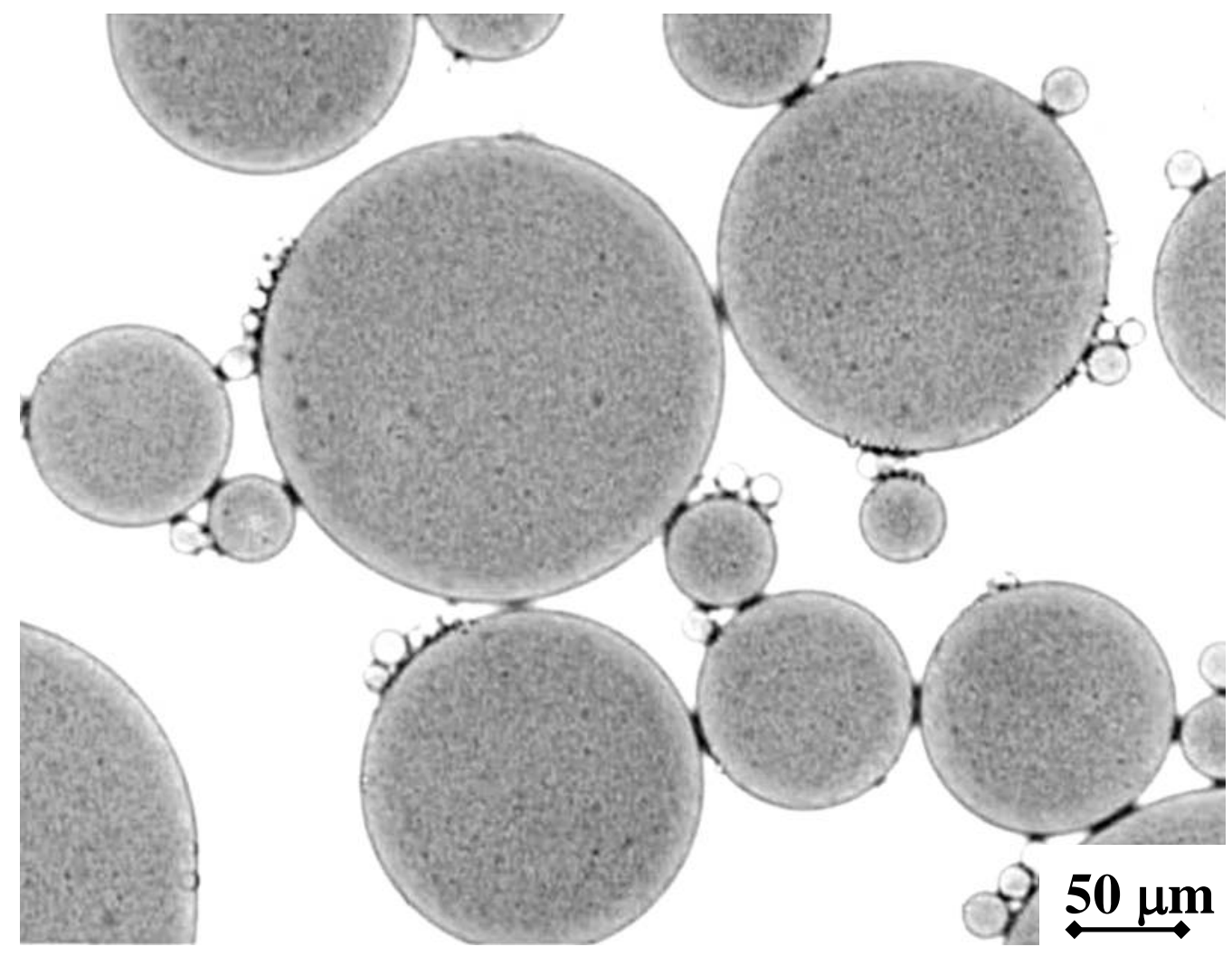

Fig. 13a, Vladisavljević et al. 


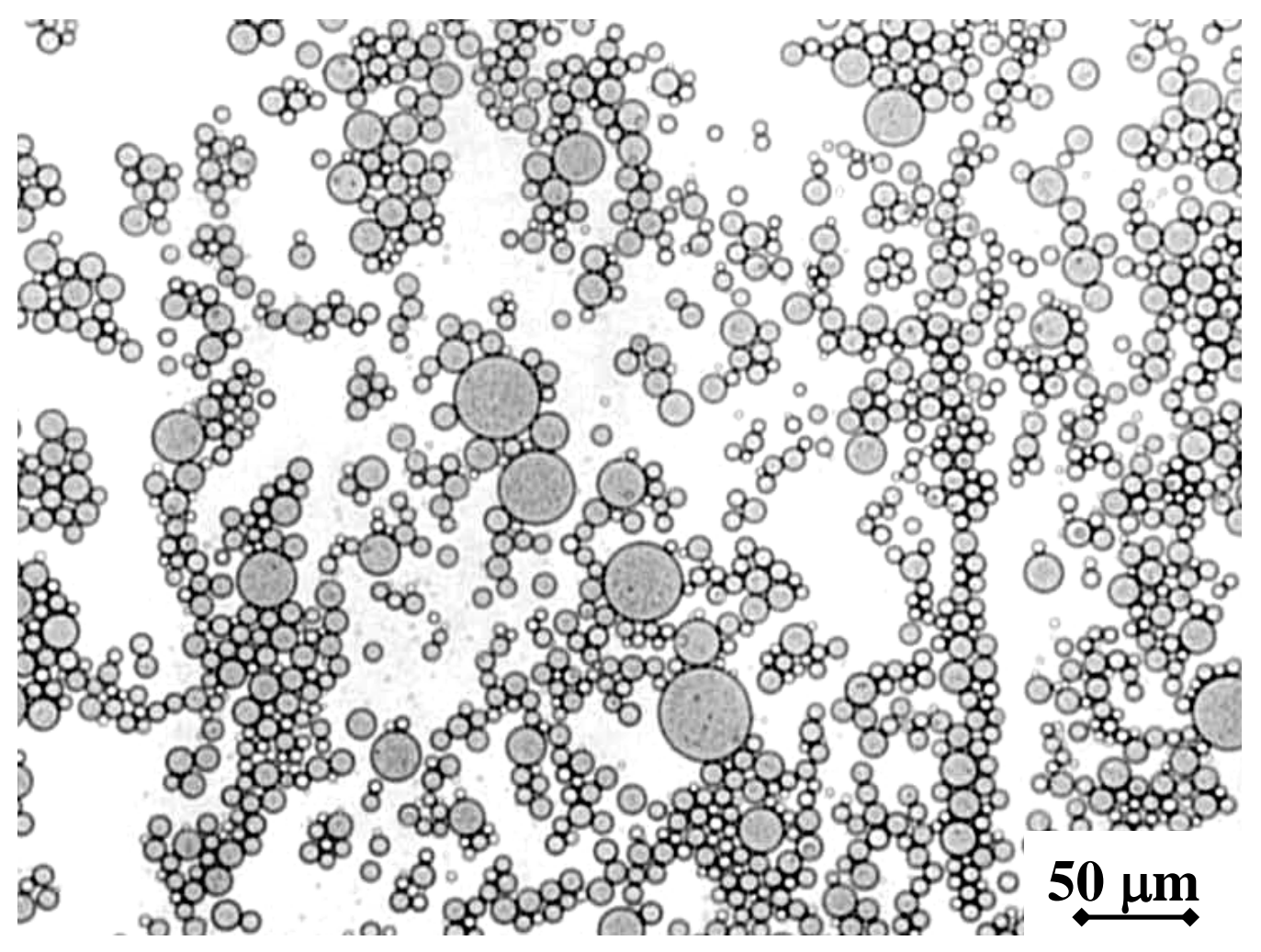

Fig. 13b, Vladisavljević et al. 


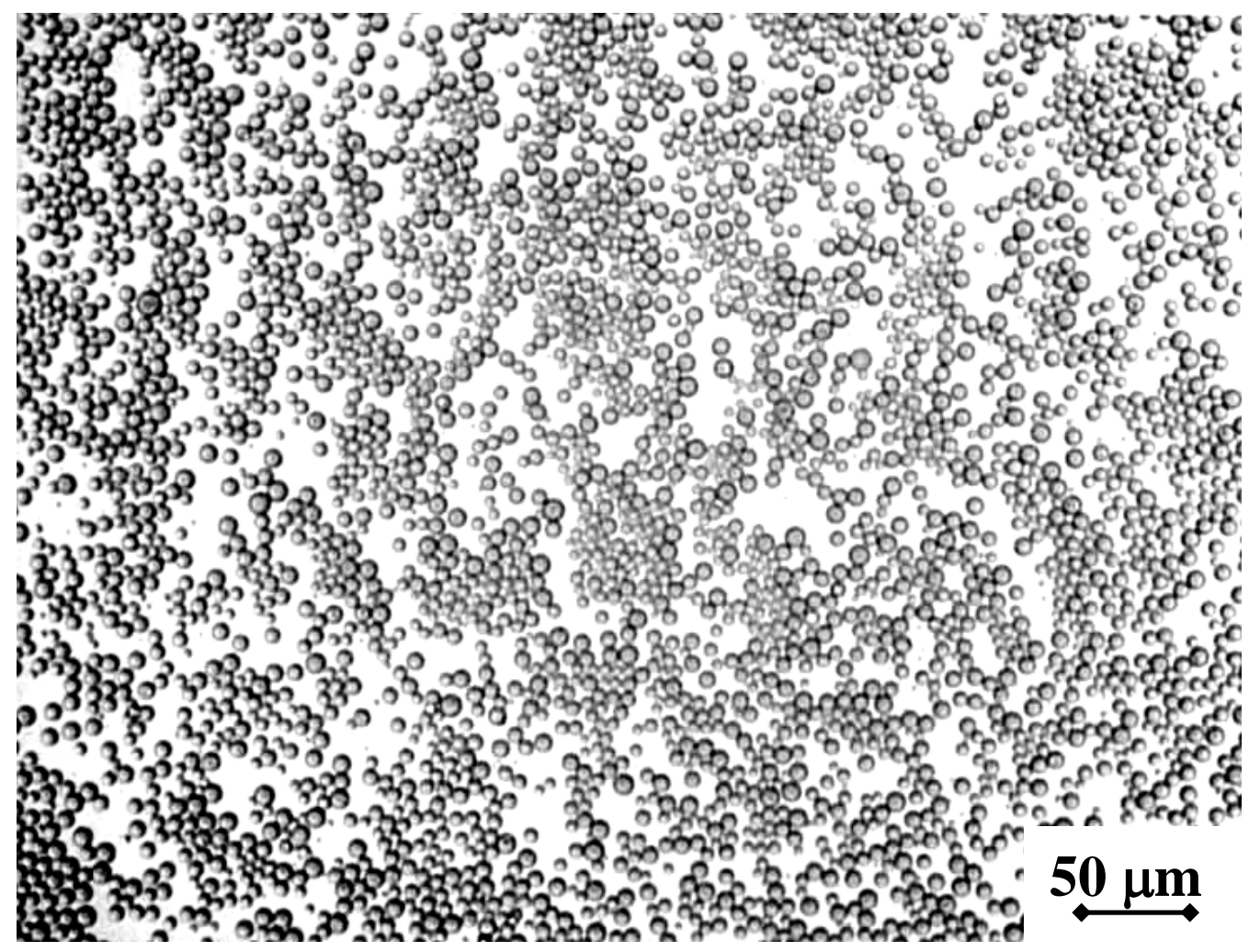

Fig. 13c, Vladisavljević et al. 